CUPAUAM. 19-1992, 319-360

\title{
FORTIFICACIONES URBANAS DE EPOCA BAJOIMPERIAL EN HISPANIA. UNA APROXIMACION CRITICA (*) (SEGUNDA PARTE)
}

\author{
CaRmen Fernandez OCHOA \\ ANGEL MORILlL CERDAN \\ DPTO. PREHISTORIA Y ARQUEOLOGIA \\ UNIVERSIDAD AUTONOMA DE MADRID
}

\section{Resumen}

El propósito de este artículo es presentar un catálogo actualizado, sistemático y crítico sobre el estado de la investigación de las fortificaciones tardorromanas de las ciudades hispanas que sirva de base para futuros estudios relacionados con esta importante parcela de la arqueología de la Hispania Romana.

\section{Summary}

The purpose of this article is to present an up-to-date, systematic and critical catalogue on the state of research about late roman fortifications of Hispanic cities, which can be used as a base for future studies related to this important area of "Hispania Romana" archeology.

\section{CATALOGO DE FORTIFICACIONES URBANAS BAJOIMPERIALES (CONTINUACION)}

\section{PROVINCIA LUSITANIA}

\section{Emerita Augusta (Mérida)}

"No puede dudarse de la existencia en Mérida de una fortificación bajoimperial reforzando el primitivo recinto del Alto Imperio..”. Con estas palabras, que nosotros suscribimos por completo, comenzaba Balil su apartado dedicado a la capital de la Lusitania en su trabajo sobre las fortificaciones bajoimperiales (Balil, 1960, 195). Sin embargo, la escasa atención que se ha

(*) Este trabajo constituye la segunda y última parte del publicado con el mismo nombre en el número anterior de la presente revista. 
prestado a este tema, denunciada un poco más adelante por el mismo autor, apenas si ha sufrido algún cambio en los últimos treinta años. Las breves líneas dedicadas por los investigadores a la muralla emeritense, han abordado la cuestión desde el punto de vista del trazado altoimperial y sus consiguientes perduraciones tardías (Almagro Basch, 1976, 200-1; Alvares Saenz de Buruaga, 1976, 37 ; Alvarez Martínez, 1981, 11-14; Alvarez Martínez, 1985, 40). Calero plantea un estudio exclusivamente historiográfico (Calero, 1992). Como consecuencia de este abandono por parte de la investigación las fortificaciones de la antigua Emerita se encuentran entre las más desconocidas de las grandes urbes hispanas bajoimperiales.

Las últimas investigaciones parecen apuntar en el sentido de que la ciudad romana nunca adoptó una planta rectangular estricta para despues desbordar el perímetro inicial de época augustea y tener que dotarse de un nuevo recinto defensivo en el Bajo Imperio. La ciudad se diseńó desde un principio con planta irregular, dejando en su interior espacios vacios para su futura expansión (Alvarez Martínez, 1981, 11-2). Esto supone que ambos recintos, el altoimperial y el tardorromano, debieron coincidir en la mayoría de los puntos del trazado.

Durante los últimos años hay algunas noticias sobre la aparición de restos de muralla en diversos lugares del casco urbano. Almagro la documentaba en la Casa del Anfiteatro, detrás de éste edificio público, en la calle Obispo Masona y en la llamada Puerta de la Villa (Almagro Basch, 1976, 201). Alvarez Martinez añade a estos puntos la Alcazaba (Alvarez Martínez, $1985,40)$. Sin embargo, los autores no se ponen de acuerdo sobre la datación de los distintos lienzos. Alvarez Martínez -el único autor que tiene en cuenta sus características constructivas- la describe con núcleo de piedras y paramento de losas de diorita bien careadas, con sillares en los puntos débiles. El recinto amurallado estaría reforzado con torres semicirculares y constaría de varias puertas, una de las cuales es la famosa puerta de la cabecera del puente (Alvarez Martínez, 1981, 12-14), conocida a través de las emisiones monetales de la colonia y recientemente excavada, aunque los resultados de estos trabajos no han sido dados a conocer. En el mismo trabajo, el autor califica de "tardía" la puerta de la calle del obispo Masona, sin explicar las razones que le llevan a esta atribución. Por su parte, Almagro Basch, documenta que el sector de muralla de la Casa del Anfiteatro arrasa muros de esta vivienda para su construcción, pero no considera posible dar una cronología cierta a la misma (Almagro Basch, 1976, 200).A Jiménez Martín se inclina asímismo por la existencia de dos murallas de dotación diferente (Jiménez Martín, 1976, 120, nota 87).

Las recientes excavaciones realizadas en la calle J. Ramón Mélida y en la Alcazaba han confirmado, al menos desde el punto de vista constructivo, la existencia de dos recintos amurallados adosados. El recinto interior, presumiblemente augusteo, está realizado en opus incertum. En un momento posterior, éste se refuerza con un paramento externo de opus quadratum y un relleno de tierra y piedras, entre las que se encuentran numerosos fragmentos arquitectónicos reutilizados. Este recinto externo sería el bajoimperial, aunque no podamos precisar su cronología hasta la publicación de los resultados de estas excavaciones (1).

Recientemente L. García Moreno ha aportado interesantes pruebas sobre la vigencia de este recinto durante la época goda (García Moreno, 1986, 98).

(1) Agradecemos a Rosalía Durán la noticia de este descubrimiento. 


\section{Ebora (Evora)}

La ciudad de Evora conserva buena parte de su recinto amurallado de época medieval, denominado "cerca velha" por sus habitantes. El primer investigador que señaló el origen romano de algunos lienzos de muralla fue Pereira (Pereira, 1885 y 1900; Ayves, 1896, 434-40). Desde estas primeras menciones, tan sólo Espanca (Espanca, 1949, 20 y 108; 1966, 5-10) y García y Bellido (García y Bellido, 1971) han prestado alguna atención a este tema. A este último autor le debemos la descripción más completa realizada hasta el momento del recinto eborense.

El perímetro amurallado de Evora presenta un trazado irregular, cuya superficie Espanca calcula en unos 1080 metros (Espanca, 1966, 5) -equivalentes a unas 7-8 has.-, y estaba reforzado con torres cuadrangulares. Se edificó en opus quadratum, con sillares de granito de proporciones canónicas dispuestos a soga y tizón (García y Bellido, 1971, 91). El lienzo oriental es el más visible en la actualidad, en parte por haber sido despejado de edificaciones adosadas (García y Bellido, 1971, 91). Al periodo romano pertenecería asímismo el arco exterior de la Porta de D. Isabel, de medio punto, 4, 35 metros de altura y 4 de anchura (Espanca, 1949, 108). García y Bellido apuntaba que la fisonomía de la Porta de Moura, flanqueada por dos torres, podía ser indicativa de un origen semejante (García y Bellido, 1971, 90). Entre la rua Nova y la rua 5 d'Outubro se abriría asímismo una poterna.

Taracena clasíficó la muralla de Evora entre las erigidas a finales del siglo II como consecuencia de los trastornos causados por la invasión de los mauri en la Bética (Taracena, 1949, 432-3). Espanca veía muy problemática la datación romana de la mayor parte del recinto, aunque consideraba que algunos lienzos podían ser "romano-godos" (Espanca, 1966, 5-7). Por su parte, García y Bellido evita pronunciarse al respecto, manteniendo unicamente su origen romano (García y Bellido, 1971). En su más reciente monografía sobre el Portugal romano, Alarcāo propone para la muralla de Evora una cronología de principios del IV, dentro de la tendencia general de fortificación de las ciudades hispanas de este momento (Alarcāo, 1988, II, 3, 159). Las excavaciones arqueológicas llevadas a cabo recientemente por V. Correia, aún inéditas, confirman esta cronología bajoimperial (2).

Ninguno de estos autores emplea criterios auténticamente arqueológicos en su visión particular del problema, sino tan sólo razones de índole histórica. En realidad estamos tan lejos de una respuesta sobre las fases constructivas del recinto defensivo de la antigua Ebora, como nos encontrabamos despues de los primeros trabajos de Pereira. La ausencia de excavaciones publicadas emsombrece cualquier interpretación al respecto.

\section{Norba (Cáceres)}

Problemas de tipo semejante ha planteado hasta hace algunos años el recinto amurallado de Cáceres, la romana Norba Caesarina. Arqueológos y eruditos han prestado por lo general poca atención al mismo. Mélida fue el primer autor moderno que señaló la existencia de lienzos con sillería romana (Mélida, 1924, 8). Richmond, que no llegó a estudiar el recinto, y Balil, lo incluyen entre los edificados en época bajoimperial (Richmond, 1931, 99; Balil, 1960, 195; Balil, 1965, 285), opinión que sigue Callejo Serrano, quien realizó una completa, aunque algo confu-

(2) Agradecemos a este arqueólogo la información sobre sus investigaciones en la muralla de Evora. 
sa, descripción de la muralla romana (Callejo Serrano, 1968). Otros trabajos de tipo histórico no aportaron nada nuevo a la cuestión (Floriano Cumbreño, 1957; Callejo Serrano, 1964). Por el contrario, las excavaciones de Beltrán LLoris en la plaza del Socorro, han supuesto un considerable avance, al aclarar definitivamente el origen romano de la obra defensiva (Beltrán Lloris, 1975-6; Beltrán Lloris, 1982, 50-2). En 1982, Salas Martín leyó su Tesis Doctoral, aún inédita, sobre la época romana en Cáceres.

El profundo enmascaramiento de la estructura romana por parte de la obra almohade dificulta excepcionalmente el seguimiento del trazado original romano. Callejo describe la planta del recinto como rectangular o trapezoidal, tal vez con torres circulares en las esquinas y al oeste dos cubos cuadrados separados de la obra general de la muralla, aunque unidos a ella por lienzos. De las puertas del recinto, la Puerta del Río -llamada comúnmente Arco del Cristo- es la única que conserva trazas de un posible origen romano. Esta entrada forma un pasadizo abovedado de medio punto, con 6, 40 metros de longitud y 3, 40 de luz del arco. Probablemente estuvo defendida por una gran torre cuadrada a su izquierda, pero el autor no se muestra partidario de la existencia de otro torreón en el lado contrario (Callejo Serrano, 1968, 126-7). Las excavaciones de la Plaza del Socorro pusieron de manifiesto otra posible puerta del recinto amurallado, de la que se conservaban dos sillares pertenecientes al arco (Beltrán Lloris, 1975-6, 104-6).

Los restos constructivos de época romana se concentran al este de la Puerta del Río y en el sector occidental de la ciudad, en la Plaza de Piñuelas y la llamada Torre del Postigo. La técnica constructiva parece ser opus quadratum a base de grandes sillares de granito dispuestos a soga y tizón, unidos a hueso, muchos de ellos reutilizados. El relleno interno es de hormigón con fragmentos de arenisca para darle consistencia. Esta estructura, documentada por Callejo en diversos puntos del recinto (Callejo Serrano, 1968, 126-30), ha sido confirmada por las excavaciones de Beltran Lloris (Beltrán Lloris, 1975-6, 104). Este autor comprueba asímismo la existencia de una banqueta de fundación con sillares en resalte, bajo la cual los lienzos se asientan sobre la roca virgen sin preparación alguna.

Respecto a la cronología de este recinto defensivo, Beltran Lloris ha corregido su tradicional atribución al Bajo Imperio (Richmond, 1931, 99; Balil, 1960, 195), adelantando el grueso de su construcción al siglo II d. C. (Beltrán Lloris, 1975-6, 107), sin, a nuestro jucio, tener base suficiente (Beltrán Lloris, 1975-6, 106-7). Esta nueva hipótesis requiere sin duda una comprobación estratigráfica, que hasta el momento no se ha realizado.

\section{Caurium (Coria)}

Las menciones a las murallas romanas de la antigua Caurium son muy frecuentes en la historiografía del XIX y comienzos del XX (Ceán Bermúdez, 1832, 409-10; Díaz y Pérez, 1887, 755-6; Martínez, 1901; Mélida, 1924, 80 y 104-6). Por el contrario la investigación moderna no ha prestado excesiva atención a este recinto, cuya estudio ha quedado en manos de eruditos locales, a los que debemos valiosas descripciones del mismo, no siempre realizadas de acuerdo con una metodología científica y, a menudo, contradictorias (Velo Nieto, 1947; Dotor, 1965). Diez Martos es el primero en dedicar un estudio específico a las murallas (Díez Martos, 1956). Thouvenot publica en 1961 una nueva descripción, que no introduce novedades sustanciales (Thouvenot, 1961). A estos trabajos debemos añadir las breves líneas dedicadas por Balil en su monografía de 1960 y las recientes observaciones de Martínez Lillo (Martínez Lillo, 1990, 
167). Hasta el momento no se ha realizado ninguna comprobación arqueológica en las murallas de Coria.

La ciudad romana de Caurium se levanta en un escalón rocoso que se prolonga sobre la margen derecha del río Alagón. La planta urbana es irregular, de aspecto poligonal, adaptada a la topografía del terreno. Sus dimensiones varían según los distintos autores: para Díez Martos, el perímetro mediría 1220 metros, lo que supondría unas 6, 5 has (Díez Martos, 1956, 276); Thouvenot lo reduce a 800 metros (Thouvenot, 1961, 333). En cualquier caso, la extensión de $1 \mathrm{ha}$. que Taracena atribuye a la antigua Caurium, parece tratarse de un error de este investigador (Taracena, 1949, 439). El recinto defensivo estaba reforzado con torres rectangulares, de 5, 50 metros de anchura, proyectadas 2,80 metros al exterior y separadas por distancias comprendidas entre 9 y 12 metros (Díez Martos, 1956, 278). Thouvenot se muestra partidario de una mayor irregularidad en las medidas de torres, cuyo frente estaría entre 4 y 5, 15 metros -sin alcanzar nunca la medida apuntada por Díez Martos- y cuyo resalte fluctúa entre los 2, 37 y los 3 metros (Thouvenot, 1961, 334). Velo y Nieto, por motivos que no podemos adivinar, se equivoca acerca de las distancias entre torres, fijándolas en 20, 25 o 30 metros (Velo y Nieto, 1947, 34). Gran parte de las torres no ha llegado hasta nosotros.

En los extremos de las dos calles principales, que teoricamente se cruzaban en el centro de la ciudad, se dispondrían cuatro puertas flanqueadas por torreones cuadrados, de las cuales sólo dos conservan la mayor parte de su estructura primitiva: la Puerta de San Pedro y la Puerta de la Guía. La Puerta de San Pedro, al noreste del recinto, presenta torres laterales de 5, 65 metros de frente y 2, 85 de resalte (Thouvenot, 1961, 288). El arco de entrada, realizado en sillería, es doble, de medio punto, con $30 \mathrm{cms}$. de separación intermedia y una luz de 4, 30 metros. Un pasillo abovedado de unos 4 metros de longitud, separa los arcos exteriores del interior, también de medio punto. Las torres se prolongan hacia el interior del recinto, ampliando la longitud del pasillo, que alcanza los 12, 50 metros. En éste se abre una pequeña puerta al interior de la muralla, que conduce al primer piso de las torres (Thouvenot, 1961, 337). La Puerta de la Guía, abierta al occidente de la fortaleza, presenta estructura y dimensiones semejantes, aunque en este caso el arco exterior es sencillo y las torres no se prolongan hacia el interior (Thouvenot, 1961, 355-6). La fachada de la puerta fue rehecha durante el siglo XVII, desapareciendo el arco externo original. Las otras dos puertas, la del Rollo - al Noroeste- y la del Sol -al sureste-, están muy transformadas, aunque esta última conserva el pasillo interior, de 3, 5 metros de luz y 4 metros de longitud (Thouvenot, 1961, 35).

A estas cuatro puertas, Díez Martos añade un posible postigo, desaparecido durante el pasado siglo (Díez Martos, 1956, 278).

Por lo que se refiere a la técnica edilicia, en su construcción se emplearon sillares graníticos de gran tamaño, dispuestos a hueso en un opus quadratum, que, sobre todo en las partes inferiores, aparece dispuesto algunas veces "a soga y tizón". Entre ellos abundan los materiales reutilizados como inscripciones, fustes y cupae. El núcleo de la estructura es de hormigón compactado con cantos rodados. La anchura total de la obra es de unos 4 metros (Thouvenot, 1961, 333). Las partes altas del recinto se recrecieron en un momento posterior con mampostería de cantos rodados y mortero (Díez Martos, 1956, 285). Thouvenot fija la altura del recinto en época romana entre 6 y 8 metros pero no se pronuncia respecto a la cronología del actual camino de ronda y su parapeto (Thouvenot, 1961, 334). En la actualidad, las torres, cuyo interior es macizo, se elevan 4 metros por encima de los lienzos. En cuanto a los cimientos, estos son poco profundos, con zarpa de cimientación de escasa altura y resalte (Thouvenot, 1961, 333). En los 
autores que se han ocupado de este recinto, la argumentación sobre la cronología del mismo se ha basado en datos indirectos de tipo constructivo y en la presencia de materiales reutilizados en la estructura de la muralla, que parecen indicar una fecha post quem (Velo Nieto, 1947, 35). Esta ausencia de datos fiables se ha traducido entre los estudiosos en cierta indecisón sobre sobre su momento de edificación. Richmond, sin estudiar directamente el recinto de Coria, lo puso en relación con el estilo "legionario" de las ciudades del Noroeste peninsular (Richmond, 1931, 99). Taracena (Taracena, 1949, 439) y Balil (Balil, 1960, 194-5) se hacen eco de esta datación en la segunda mitad del siglo III. Este último autor la clasifica dentro del grupo de las fortificaciones hispanas que siguen el primer estilo de las murallas aurelianas de Roma, señalando sus estrechos paralelos tipológicos con las murallas de Barcino. Díez Martos retrasa esta fecha hasta comienzos del siglo $\mathrm{V}$, momento de la invasión de suevos, vándalos y alanos (Díez Martos, 1956, 291-3). Thouvenot recoge ambas posibilidades, si bien se inclina por el siglo III (Thouvenot, 1961, 338-9). Recientemente, Martínez Lillo, interpretando algunos aspectos inéditos de la técnica constructiva ha planteado ciertas dudas sobre el origen romano del recinto amurallado (Martínez Lillo, 1990, 167).

Esta disparidad de criterios es fruto de la ausencia de auténticos estudios arqueológicos que aporten datos fiables para fundamentar cualquier hipótesis cronológica. Mientras estos no se lleven a cabo no podremos pronunciarnos sobre el carácter bajoimperial de esta fortaleza.

\section{Cappara (Cáparra, Plasencia, Cáceres)}

La ciudad romana de Cappara se levantaba en terreno llano, junto al río Ambroz y a poca distancia de la actual Plasencia. Floriano Cumbreño, que visitó las ruinas en 1929, hablaba de la existencia de restos de un recinto defensivo irregular, semejante a un pentágono, con muros de 3, 20 metros de anchura realizados con sillares almohadillados colocados a soga y tizón. Los lienzos mejor conservados se encontraban al noreste y al suroeste (Floriano Cumbreńo, 1944, 272-4). Durante las excavaciones de Blázquez en la década de los sesenta, nada de esta muralla se encontraba ya a la vista, lo que no fue obstáculo para que este investigador informara de su datación bajoimperial, enmarcada dentro de un amplio programa de fortificaciones estratégicas en la Lusitania (Blázquez, 1965, 11). Ese mismo año Balil afirmaba sobre este recinto que: “...en todo caso no puede atribuirse al Bajo Imperio" (Balil, 1965, 285). En el estado actual de la investigación carecemos de cualquier dato objetivo sobre la cronología de esta muralla.

\section{Augustobriga (Talavera la Vieja, Cáceres)}

Tan sólo Blázquez apunta el carácter tardío de este recinto (Blázquez, 1966, 11), lo que ningún argumento arqueológico o estratigráfico (García y Bellido, 1962), parece confirmar.

\section{Civitas Igaeditanorum (Idanha-a-Velha, Portugal)}

La antigua Civitas Igaeditanorum o Egitania se encuentra rodeada hoy en día de una potente muralla, muy bien conservada en la mayor parte de los sectores, a la que algunos autores han supuesto un origen romano. Sin embargo, a pesar de los casi veinte años de excavaciones arqueológicas que Almeida dedicó a aclarar diversos aspectos del pasado de la actual Idanha-a-Velha, no existe ningún trabajo específico dedicado al recinto amurallado, reduciéndose nuestra informa- 
ción a varias noticias breves publicadas en artículos y obras de conjunto (Pereira, 1938; Correia, 1945; Almeida, 1956 a; Almeida, 1956 b, 14; Almeida, 1965; Almeida, 1977). Alarcāo describe someramente este recinto en sus monografías (Alarcāo, 1973; Alarcāo, 1988).

La muralla presenta una planta irregular, de tipo ovalado, adaptada a la topografía de la elevación del terreno que ocupa Idanha-a-Velha. Alarcāo cifra la longitud de su perímetro en 754 metros (Alarcāo, 1988, II, 1, 74-5). Carece casi por completo de torres, a excepción de dos cubos de flanqueo en sus puertas, uno rectangular y otro redondo. Al parecer existieron tres puertas y una pequeña poterna. Esta última se encuentra junto a la puerta occidental, al otro lado de la torre rectangular de flanqueo (Almeida, 1956 a, 88-9). No parece haber huellas de una torre gemela en el lado derecho de esta puerta (Alarcāo, 1973). El arco es de medio punto. Una segunda puerta se abre en el lienzo septentrional, justo al lado de la carretera de acceso a esta localidad. Esta puerta, que consta de un largo corredor de 5 metros de longitud por cerca de 1 de anchura, sostenido por tres arcos de medio punto, estaba protegida por una torre redonda y hueca. Detrás del arco exterior se conserva el hueco para el rastrillo. Almeida, aunque la describe, no llega a reflejarla en su plano de 1965 (Almeida, 1956 b, 89). En el lado oriental debió existir una tercera entrada, de la que sólo se ha conservado su carácter de zona de paso.

La técnica edilicia no es uniforme en todos los sectores del recinto. En algunas zonas el muro alcanza los 4, 50 metros de anchura (Pereira, 1938, 197), construido con sillería granítica dispuesta "a soga y tizón" y núcleo de hormigón. En otros puntos, especialmente en la zona noroeste, el grosor no llega a los 2 metros, realizado con dos filas de sillares de gran tamaño unidos en seco y dispuestos de la misma manera que en los tramos anchos. El aspecto exterior resulta muy homogéneo. Los sillares y elementos arquitectónicos reutilizados son muy abundantes. En algunos puntos los lienzos alcanzan los 6 metros de altura. No hay huellas visibles de banqueta de cimentación.

Los distintos investigadores se mueven en una total confusión respecto a la cronología de este recinto defensivo. Pereira (Pereira, 1938,192-3) y,en un primer momento, Almeida (Almeida, 1956 a 119) se muestran partidarios de una edificación de época medieval. Posteriormente, este mismo investigador corrige su datación original, apuntando un origen romano para las murallas (Almeida, 1965, 409). Alarcāo, trás un primer momento de duda (Alarcāo, 1973, 96), se decanta por una construcción romana, apuntando incluso el siglo IV d. V. como fecha de la misma (Alarcāo, 1988, II, 1, 74-5). En este mismo sentido podría interpretarse la observación de Pereira en el sentido de que todo el material epigráfico es romano clásico, faltando lápidas cristianas (Pereira, 1938, 192-3).

Obviamente ninguna de estas hipótesis ha sido avalada desde el punto de vista arqueológico y, por lo tanto, no pasan de ser meras especulaciones. Por otra parte, la estructura constructiva de esta muralla se aparta en algunos aspectos -como el de la carencia de torres- de las normas habituales en los recintos defensivos bajoimperiales, si bien el criterio estilístico no es en modo alguno aceptable por sí mismo. Las dos estructuras constructivas que se documentan en la obra de la muralla podrían indicar la existencia de al menos dos fases constructivas, tal vez una romana -la correspondiente a los sectores con núcleo de hormigón- y otra medieval -las dos filas de sillares sin relleno interno-. Sin embargo, la desaparición por completo de la primera fase supuestamente romana en algunos sectores plantea interrogantes de difícil solución. De nuevo en este caso la carencia de excavaciones arqueológicas impide formular opiniones más sólidas al respecto. 


\section{Conimbriga (Condeixa-a-Velha, Portugal)}

El recinto romano de Conimbriga se encuentra entre los más imponentes y mejor conservados de la Península. Es por este motivo por el que llama tanto la atención el aparente desinterés que ha demostrado hacia el mismo la investigación lusa. En realidad carecemos incluso de una descripción pormenorizada de la estructura defensiva. El trabajo de Correia (Correia, 1940-1) supuso un modesto intento en este sentido, sin continuación hasta la publicación del capítulo correspondiente a la arquitectura en la gran monografía de Alarcāo y Etienne (Alarcāo-Etienne, 1977). El resto son tan sólo noticias dispersas, repartidas por una serie de trabajos españoles y portugueses (Boletim dos Monumentos Nacionais, 1948; García y Bellido, 1948; Correia, 1952). El estudio de Alarcāo y Etienne, sin ir demasiado lejos, daba a conocer algunas características constructivas del recinto defensivo. La más reciente publicación de Alarcão (Alarcão, 1988, II, $1,100)$ resulta decepcionante en lo que se refiere a esta cuestión, . De forma paradójica, la descripción más completa sobre el recinto amurallado de Conimbriga se encuentra en la última guía turística del yacimiento, donde se ofrece por primera vez un esbozo de la secuencia evolutiva de las obras defensivas de esta ciudad (Moutinho Alarcāo, Mayet y Nolen, 1989).

La Direç̧ao Geral dos Edificios e Monumentos Nacionais publicó en 1948 un excelente plano de la ciudad, única referencia que tenemos para conocer algunos aspectos concretos de la muralla.

El recinto conimbrigense es de planta irregular, perfectamente adaptado a la topografía del espolón rocoso de formatriangular, inaccesible por sus lados norte y sur, ocupado por el núcleo urbano (Correia, 1940-1, 263). Su superficie es de unas 9 has. En el sector oriental, el más vulnerable, la muralla estaba reforzada con torres cuadradas, cuyas dimensiones no han sido proporcionadas por ningún autor (Correia, 1940-1). Las pequeñas torres o contrafuertes que Correia observaba en el lado sur, hoy en día sabemos que en efecto corresponden a los contrafuertes del muro de cierre meridional de la palestra, que fue incluido en la muralla tardía (Alarcăo y Etienne, 1977, 153-4). Al este del recinto se abren dos puertas localizadas durante las excavaciones de 1930-8. La principal esta flanqueada por dos torres rectangulares, que definen un paso de 8 metros de longitud y 4 de anchura (Correia, 1940-1, 263; Moutinho Alarcāo, Mayet y Nolen, 1989, 6). La segunda puerta era mucho más sencilla, sin torres laterales.

Las hiladas inferiores de la muralla se edificaron con grandes sillares de tufo, dispuestos en opus quadratum. Sobre éstas se dispone una obra de opus vitatum, bien tallado y dispuesto en hiladas regulares, en las que alterna algún sillar de tamaño mayor. La parte baja de la puerta principal emplea la sillería, aunque desconocemos el paramento de su parte superior, totalmente desaparecido. El relleno interno de la estructura se realizó con piedras planas unidas con un mortero muy compacto. El ancho de la muralla es de unos cuatro metros y en algunos puntos alcanza los 8 de altura (Correia, 1940-1, 262-3). Entre los sillares empleados en su construcción se encuentran numerosos materiales reutilizados.

Sobre la cronología bajoimperial de este recinto no parecen existir dudas entre los investigadores. La muralla corta parte de las lujosas viviendas del sector oriental, lo que, unido a la reutilización de materiales altoimperiales, constituye una fecha post quem irrebatible, aunque el momento concreto sea difícil de precisar. Taracena (Taracena, 1949, 438) y Balil (Balil, 1960, 193) la incluyen en sus catálogos. Correia la atribuye a un momento de peligro, sin precisar si se trataría del siglo III o de comienzos del V (Correia, 1940-1, 262-3). El volumen de la Direç̧cao Geral dos Monumentos Nacionais, publicado en 1948, la sitúa a comienzos del siglo V d. C. $(1948,9)$. 
Los autores que se han ocupado recientemente de esta cuestión adelantan la fecha de construcción hasta época tetrárquica, a juzgar por el aprovechamiento como lienzo del muro de cierre del edificio termal (Alarcão y Etienne, 1977, 153-4) y, sobre todo, por el hallazgo de monedas del siglo III y comienzos del IV en las viviendas que amortiza la muralla (Moutinho Alarcáo, Mayet y Nolen, 1989, 8). Alarcão defiende sin titubeos que en época bajoimperial tuvo lugar una importante reducción del perímetro urbano, prueba de lo cual sería el abandono del recinto defensivo altoimperial y la edificación de uno nuevo deshaciendo edificios anteriores y aprovechando otros, que responde mejor a las necesidades defensivas de la ciudad (Alarcao, 1988, II, 1, 100). Esta sería destruida definitivamente por los suevos en el año $468 \mathrm{~d}$. C.

Aunque la datación bajoimperial del recinto conimbrigense queda fuera de toda duda, éste aún sigue planteando notables carencias. La ausencia de datos estratigráficos más precisos sobre su edificación constituye sin duda la más destacada.

\section{Aeminium (Coimbra)}

Las investigaciones sobre la antigua Aeminium demuestran de manera cada vez más clara la profunda remodelación que sufrió la ciudad durante los siglos III y IV, como atestigua su criptopórtico (Bairrao Oleiro, 1955-6) y su acueducto. Recientemente Alarcāo apunta la posibilidad de que también las murallas de Coimbra puedan tener un origen bajoimperial, aunque no ofrece ningún argumento sólido a favor de esta hipótesis (Alarcão, 1988, II, 1, 95). La ausencia de investigaciones sobre el recinto amurallado dificulta cualquier respuesta a este problema.

\section{PROVINCIA GALLAECIA}

\section{Bracara Augusta (Braga)}

Aunque ningún resto de las murallas bracarenses ha llegado hasta nosotros, gracias a Contador de Argote conocemos una descripción bastante precisa de lo que se conservaba de ellas a comienzos del siglo XVIII (Contador de Argote, 1728, 68; Contador de Argote, 1747, 222). A principios del presente siglo aún resultaban visibles veinte metros (Bellino, 1909, 1-3). Teixeira levantó la primera planta del supuesto perimetro de la muralla romana, aunque no llegó a publicarla (Teixeira, 1910, ref. Rigaud de Sousa, 1973, 10, nota 17). Los trabajos más recientes (Do Carmo Sampaio, 1962; Rigaud de Sousa, 1973; Barreto Nunes, 1978; Tranoy, 1981, 409-10) se limitan a parafrasear los textos antiguos, sin aportar ninguna novedad al respecto, salvo tal vez la significativa localización de las necrópolis llevada a cabo por Rigaud de Sousa (Rigaud de Sousa, 1973, 12-8).

De las escuetas noticas proporcionadas por los eruditos puede desprenderse que el recinto amurallado adoptaba una planta ovalada y se extendía al sur de la ciudad medieval, que sufrió un interesante desplazamiento en dirección septentrional, desbordando en este sector el perímetro de la antigua muralla romana. Tan sólo en su mitad septentrional coincidiría la ciudad romana con el núcleo urbano moderno, heredero directo del medieval (Rigaud de Sousa, 1973, 11-2). La continuidad del hábitat urbano en este sector ya había hecho desaparecer cualquier resto de fortificación en tiempos de Contador de Argote. Este autor le daba una circunferencia de 16 estadios -unos 2000 metros-, de los cuales se conservaban 500 pasos. La anchura de la obra, realizada en mampostería ligada con fuerte mortero, era de 23 palmos $-4,80$ metros- y se 
conservaban, según los lienzos, entre 10 y 25 palmos de altura -2 y 5 metros-. La muralla estaría reforzada con torres de forma desconocida (Contador de Argote, 1728, 68; 1747, 222). Bellino debe equivocar el espesor de la muralla, que fija en 1, 50 metros (Bellino, 1909, 2). Sobre las puertas, tan sólo conocemos las descripciones medievales que pueden hacer referencia a la ciudad de este momento. Un documento de la época de Alfonso II el Casto habla de dos puertas protegidas con torres y abiertas al este y al oeste (Contador de Argote, 1728, 68).

Do Carmo informaba en 1962 del hallazgo y destrucción, pocos meses antes, de un fragmento de muralla (Do Carmo, 1962, 262). Por su parte Rigaud identifica como posible resto de la misma un potente cimiento situado al norte de la rua de Santos da Cunha (Rigaud de Sousa, $1973,11)$. Sin embargo, la primera constatación arqueológica de la fortificación bracarense ha tenido lugar durante las campañas realizadas en 1982-1983 en la llamada Quinta do Fujacal, zona tradicionalmente considerada límite sur del perímetro amurallado (Delgado y VV. AA., 1984, 101-2; Gaspar, Sande Lemos y Delgado, 1986, 39-41). Los trabajos de estos investigadores han descubierto una potente estructura de 12 metros de longitud, realizada mediante dos paramentos externos separados por un relleno interno de grandes bloques graníticos y cascote de pequeño tamaño. El paramento interno, de unos $50 \mathrm{cms}$. de anchura, está construido con grandes bloques petreos ligados con piedras más pequeñas en su parte inferior, y piedras de talla y dimensiones irregulares en parte alta. La anchura de la muralla así como el aparejo del paramento exterior no pudieron comprobarse por la presencia de un muro de contención moderno. La estructura alcanza en algunos puntos los 4, 20 metros de anchura. Entre los elementos arquitectónicos empleados en su edificación se encuentran materiales arquitectónicos reutilizados.

Los arqueólogos no han encontrado datos estratigráficos que puedan datar esta estructura aunque aseguran que "Quanto às necrópoles por nós encontradas nao contrariam a sua existência e confirmam o perímetro oblongo da cidade, já em finais do séc II/ inicios do séc. III d. C." (Gaspar, Sande Lemos y Delgado, 1986, 41). M. Martín opina que la muralla bajoimperial ocupó una superficie más amplia que el trazado ortogonal del Alto Imperio, tal vez debida a la inclusión de barrios periféricos y que su edificación debió tener lugar entre mediados y finales del siglo III d. c. (3). Esperamos que nuevas comprobaciones en otros puntos del perímetro amurallado de la antigua Bracara Augusta permitan aclarar aspectos de su trazado y de su edificación, confirmando la más que probable cronología bajoimperial de esta muralla.

\section{Aquae Flaviae (Chaves)}

La posibilidad de un origen bajoimperial del recinto amurallado de Chaves a partir de los materiales romanos embutidos en el mismo ha sido planteada por Tranoy (Tranoy, 1981, 410). Carecemos de otras noticas al respecto.

\section{Lucus Augusti (Lugo)}

Probablemente, el recinto romano de Lugo es el mejor conservado de la Península entre los de esta época y su aspecto aún responde, en buena medida, a su fisonomía original. Esta peculia-

(3) Agradecemos a M. Martins esta información inédita. 
ridad de las murallas lucenses ha sido mencionada por cronistas y eruditos desde el siglo XVI, noticias éstas exhaustivamente recopiladas por Arias Vilas (Arias Vilas, 1972, 17-22). El primer investigador moderno que prestó su atención a este recinto fue Mélida, que publicó el primer plano del perímetro (Mélida, 1921; Mélida, 1945, 42-6), seguido, varios años más tarde por Richmond (Richmond, 1931), cuyo estudio aún se encuentra entre los más valiosos desde el punto de vista científico. También de gran interés es el de Vázquez Seijas, aparecido en 1955 (Vázquez Seijas, 1955, 17-91). Otras publicaciones de menor interés aparecen recogidas en el mencionado trabajo monográfico de Arias Vilas, comparable al de Balil para las murallas barcelonesas, y que hoy en día continúa siendo una referencia imprescindible para el conocimiento del recinto forticado de Lugo (Arias Vilas, 1972). A partir de la publicación de este estudio tan sólo han aparecido guías y aportaciones de menor relevancia (De Abel Vilela, 1975 a; De Abel Vilela, 1975 b; Carreño, 1991).

El perímetro amurallado de Lugo es de unos 2120-2140 metros, abarcando una superficie de 28 has. Adopta planta cuadrangular con esquinas redondeadas, aunque su adaptación al terreno provocó alguna irregularidad en el trazado y en el espesor de algún lienzo (Arias Vilas, 1972, 53 4). La muralla estaba reforzada con torres semicirculares, que debieron alcanzar el número de $85 \mathrm{u}$ 86 , separadas por distancias que fluctúan entre 8,80 y 16, 40 metros. Por su tamaño, las torres pueden agruparse en dos grupos: con diámetros en torno a los 10,15 metros, y con diámetros que rondan los 13, 40 metros (Richmond, 1931, 88; Arias Vilas, 1972, 56). Los cubos más grandes se concentran en el sector noroccidental, mientras los más reducidos lo hacen en el oriental. Se conservan restos del piso alto en una de las torres, en la que se abren dos ventanas de 1,50 de altura por 1 metro de ancho, pero Richmond todavía observó cuatro ventanas (Richmond, 1931, 88), y testimonios anteriores hablan de torres de dos pisos con cuatro ventanas cada uno (Arias Vilas, 1972, 57). Carecemos de información acerca de las cubiertas, aunque Richmond, basándose en razones de táctica militar, no cree posible la existencia de tejados planos y almenados, poco acordes con una estrategía basada en el "fuego cruzado" (Richmond, 1931, 88). En las obras de restauración y acondicionamiento llevadas a cabo en el recinto durante los años sesenta se ha podido documentar la existencia de cuatro escaleras de acceso al camino de ronda en el interior de las torres. Dos escaleras más con estas características han sido recientemente descubiertas (Carreño, 1991, 112) este dato viene a corroborar la opinión formulada por Arias Vilas al respecto (Arias Vilas, 1972, 59-60). No se ha podido aclarar si las escaleras exteriores y la rampa que apuntaba este investigador son obra romana o posteriores. Sobre la disposición y estructura del camino de ronda, así como del sistema de cubrición de las torres todo son hipótesis (Arias Vilas, 1972, 59).

Tanto Richmond como Arias Vilas reducen a cuatro el número de las puertas romanas conservadas en la actualidad (Richmond, 1931, 89; Arias Vilas, 1972, 58). La llamada Puerta Miña, en el centro del lado occidental, es la única que mantiene su aspecto primitivo, aunque las otras tres debieron adoptar una fisonomía muy semejante. El lienzo donde se aloja la Puerta Miña es más estrecho -3, 60 metros-, está retranqueado hacia el interior y flanqueado por dos torres semicirculares edificadas con silleria dispuesta "a soga y tizón". Entre ellas se abren dos arcos de medio punto de 3,67 metros de anchura, sobre los que correría un piso cubierto que enlazaba con el piso más bajo de las torres, quedando a la altura del actual camino de ronda, destinado a albergar la maquinaria del rastrillo (Arias Vilas, 1972, 59) como bien apuntó ya Richmond (Richmond, 1931, 89). Las otras tres puertas, la Puerta Nueva, la Puerta de San Pedro y la Puerta de Santiago se encuentran muy reformadas. No parecen quedar huellas de poternas (Arias Vilas, 1972, 60). 
El aparejo constructivo consta de dos paramentos laterales y un relleno interno a base de tierra, cascote y piedras de diferentes tamaños, entre las que pueden identificarse restos de materiales epigráficos y arquitectónicos. El paramento interior es sillarejo de pizarra, mientras el exterior combina las lajas de pizarra unidas por tierra o por argamasa de mala calidad con la sillería de granito dispuesta “ a soga y tizón”, especialmente en los alrededores de las puertas. Los sillares debieron ser en un principio más numerosos, pero han sido saqueados en muchos puntos y sustituidos por pizarra (Richmond, 1931, 86; Arias Vilas, 1972, 54-5). En cualquier caso no parece válida la hipótesis de Vázquez Seijas en el sentido que la estructura primitiva se realizó en sillería de granito, siendo modificada en época posterior (Vázquez Seijas, 1955, 51). Estas mismas características constructivas son aplicables a las torres. La anchura de la muralla no es regular en todo el recinto y varía entre los 3, 20 y 4, 45 metros. Su altura alcanza casi los 6 metros en los puntos más altos (Arias Vilas, 1972, 31-43), aunque Richmond indicaba que llegaba a los 14 metros en las torres (Richmond, 1931, 86). Las lápidas y elementos arquitectónicos reutilizados son muy numerosos.

Durante las operaciones de limpieza del lienzo situado a la derecha de la Puerta de San Pedro, fue posible comprobar la existencia de cimientos, consistentes en una hilada de cantos rodados, lajas pizarrosas colocadas en sentido vertical y piedras de gran tamaño dispuestas sobre una capa de tierra arcillosa que apoya directamente sobre el suelo natural, estructura que facilita el drenaje. Este hallazgo le lleva a Arias Vilas a desestimar la existencia de un foso (Arias Vilas, 1972, 9).

Por lo que respecta a la cronología de este recinto, todos los investigadores parecen estar de acuerdo en su origen bajoimperial. Mélida lo puso en relación con la primera fase de las murallas aurelianas de Roma (Mélida, 1921). Richmond, a partir de los restos epigráficos empotrados en la muralla lo data entre el 250 y el $325 \mathrm{~d}$. C., clasificándolo entre los ejemplos más claros del "estilo legionario" hispánico (Richmond, 1931, 90). Taracena (Taracena, 1949, 437-8) y Balil (Balil, 1960, 193) se hacen eco de esta datación, al igual que Arias Vilas (Arias Vilas, 1972, 113), que concreta la fecha post quem para su edificación, llevada a cabo entre el 260 y el $310 \mathrm{~d}$. J. C. La presencia en Lugo de la Cohors Lucensis a principios del siglo V, conocida a través de la Notitia Dignitatum (XLII, 1, 29), hablaría en favor de cierto carácter militar de esta fortificación, que aún está por definir.

Cuestión muy relacionada con la cronología del recinto lucense es la posible existencia de un recinto defensivo altoimperial. Arias Vilas, ante la homogeneidad constructiva y la uniformidad morfológica de las torres, asegura que existe un único periodo constructivo, correspondiente a la muralla bajoimperial (Arias Vilas, 1972, 53). No podemos entrar aquí en la controvertida cuestión de la existencia en Lugo de un primer recinto defensivo de carácter militar, por otra parte ya abordado recientemente en otro lugar (Morillo, 1991, 167), pero, en cualquier caso, éste no sería el bajoimperial.

En resumen, debemos considerar las murallas bajoimperiales de Lugo como una de las mejor estudiadas desde el punto de vista constructivo, aunque la carencia de comprobaciones arqueológicas de la envergadura de las realizadas en Barcelona o Gerona -por poner tan sólo algunos ejemplos- ensombrezcan de manera significativa nuestro conocimiento sobre el origen y cronología de las mismas. Esperamos que futuras excavaciones sistemáticas acometidas en este recinto, -que parece haber sido abandonado por la investigación desde la publicación del trabajo de Arias Vilas-puedan proporcionar bases más firmes que las dataciones a posteriori. 


\section{Castra Legionis VII Geminae (León)}

El recinto murado de León ha sido considerado, junto con el de Lugo, como uno de los ejemplos más paradigmáticos de murallas tardorromanas hispánicas, aún cuando su estructura original ha sido profundamente alterada en época medieval. En la actualidad se conservan más de tres cuartas partes del mismo, ocupado por el núcleo medieval antiguo, del que fue límite y perímetro defensivo durante varios siglos. Desgraciadamente, el interés de la investigación no ha ido paralelo a la importancia de esta estructura, de excepcional valor para aclarar ciertos tópicos de la investigación sobre la técnica edilicia "militar" de época bajoimperial. Si exceptuamos algunas descripciones sumarias, realizadas con métodos no siempre acordes con las necesidades científicas (Gómez-Moreno, 1925, 23-4; Mateo Marcos, 1979; Mateo Marcos, 1981), los únicos investigadores que se han ocupado de las murallas leonesas desde un punto de vista arqueológico han sido Richmond, a quien debemos la primera descripción pormenorizada del recinto (Richmond, 1931, 90-4) y García y Bellido, que realizó diversos sondeos con motivo de la celebración del decimonoveno aniversario de la fundación de la Legio VII Gemina (García y Bellido, 1968 a, rep. y amp. 1970; 1968 b). Taracena (Taracena, 1949, 437) y Balil (Balil, 1960, 192-3 la incluyeron en sus repertorios de ciudades bajoimperiales amuralladas. Hace algunos años, Matilla Vicente se limitó a hacer un estado de la cuestión, sin aportar nada nuevo (Matilla Vicente, 1983).

El origen de la muralla leonesa habría que buscarlo en la existencia de un campamento permanente de la Legio VII Gemina en este lugar durante más de cuatro siglos, cuya presencia esta avalada a comienzos del siglo V por la Notitia Dignitatum (XLII, 1, 25). Las cannabae legionarias se convertirían en ciudad al menos desde mediados del siglo III, momento en el que se puede documentar la presencia de magistrados civiles (García y Bellido, 1968 b, s/p).

La ciudad de León se asienta en una colina elevada a poca distancia de la confluencia entre los ríos Bernesga y Torio. Su recinto amurallado, que encierra algo menos de 20 has., presenta una planta rectangular con esquinas redondeadas y ejes de 570 X 350 metros, siguiendo el teórico esquema campamental de Higinio. Su perímetro total es de unos 1400 metros, aunque este dato resulta difícil de precisar debido a la casi total desaparición de uno sus lados menores, concretamente el meridional (García y Bellido, 1968, 9). Gómez-Moreno (Gómez-Moreno, 1925, 23-4) y Richmond (Richmond, 1931, 91) ofrecen unas medidas algo distintas. Los lienzos, conservados hasta una altura de 5, 5 metros, están reforzados con torres semicirculares, de 8, 25 metros de diámetro, de las que han llegado hasta nosotros 31 de las 74 a 78 que debió tener (Richmond, 1931, 91-3). Los intervalos entre ellas son de 15 metros, distancia que se mantiene muy regular. No se ha conservado ninguna puerta del recinto, pero la topografía urbana mantiene el recuerdo de su existencia (Richmond, 1931, 93).

Las excavaciones realizadas por García y Bellido a lo largo de la década de los sesenta revelaron datos fundamentales acerca de su aparejo y técnica constructiva. Las murallas estaban constituidas por dos muros adosados, ambos con núcleo de piedra y hormigón. El interior es un pequeño muro de 1, 80 metros de anchura, cuyo aparejo exterior es de sillarejo muy bien escuadrado, con las juntas encintadas. Un segundo muro, posiblemente realizado en opus quadratum (Richmond, 1931, 91) pero cuyo aspecto actual es de un aparejo de piedras mal labradas con algunos sillares y elementos epigráficos y arquitectónicos reutilizados, envuelve y enmascara al anterior por su cara externa. En algunos puntos los sillares se colocan "a soga y tizón". Con este segundo muro, la anchura total de la muralla es de 5, 25 metros (García y Bellido, 1968 a, 13). 
En 1961, en un sondeo en la torre vecina a Puerta Renueva, García y Bellido pudo comprobar la existencia de una banqueta de cimentación de un metro de anchura por uno de profundidad, bajo la cual continuaban los cimientos, que alcanzan 2, 70 metros de profundidad. El material de construcción de ambos elementos -banqueta y cimientos- era la mampostería. Este hecho se pudo comprobar en otros puntos del recinto, como en la plaza del Cid (García y Bellido, 1968 a, 13-4 y 25).

Aunque Gómez-Moreno no se mostraba partidario del origen romano del recinto, al menos en lo que a su aspecto exterior se refería (Gómez-Moreno, 1925, 23-4), Richmond, a partir del análisis de los restos epigráficos, atribuyó su construcción al periodo bajoimperial (Richmond, 1931, 93-4). Esta opinión ha sido mantenida sin cambios hasta nuestros días (Taracena, 1949, 437; Balil, 1960, 192-3; García y Bellido, 1968 a, 15-6). Las excavaciones de Garcia y Bellido, aunque confirmaron arqueológicamente la hipótesis de Richmond sobre la cronología romana del recinto, abrieron nuevos ámbitos de discusión. La indiscutible existencia de dos muros adosados, realizados con técnica muy diferente, plantea interrogantes de difícil solución sobre la fortificación romana leonesa. García y Bellido, interpretaba que el muro de 1,80 , claramente anterior al muro externo, sería una primera muralla defensiva levantada sin prisa a finales del siglo III o comienzos del IV y ampliada apresuradamente ante la amenaza bárbara a finales de este mismo siglo. Este autor se plantea con extrañeza las razones que podrían haber llevado a la edificación de una primera muralla tan pequeña y sólo encuentra una respuesta en el carácter militar del asentamiento de León, que no hacía necesarias mayores defensas (García y Bellido, 1968 a, 15-6).

$\mathrm{La}$ ausencia de datos arqueológicos quecorroboren esta hipótesis la convierten en una simple especulación razonada. En realidad, en el momento actual de la investigación -que es prácticamente el mismo que en época de García y Bellido-, carecemos de datos suficientes que permitan llegar a conclusiones más sólidas. Los numerosos puntos de contacto entre la estructura defensiva legionense y las murallas de Barcelona, plantean significativas cuestiones, que podrían cifrarse en la posibilidad de una cronología altoimperial para el primer recinto de León, lo cual no está avalado por ningún resto. Por otra parte, la erección de las murallas parece vinculada, al menos desde el punto de vista cronológico, a la municipalización del antiguo solar del campamento, que, a juzgar por los datos disponibles, debió tener lugar durante el siglo III. Desconocemos si fue su carácter civil o su funcionalidad militar la que impulsó el amurallamiento del recinto.

Las profundas modificaciones medievales efectuadas sobre el aparejo externo plantean fundadas dudas sobre si su aspecto actual responde de alguna manera al original romano o si las sucesivas reconstrucciones lo han desvirtuado por completo.

\section{Asturica Augusta (Astorga)}

El recinto amurallado de Astorga es, entre los del noroeste, el que mayores problemas plantea. Conserva algo más de la mitad de su perímetro, pero su aspecto actual corresponde a las reformas del siglo XIII. Gómez-Moreno lo atribuye a época medieval (Gómez-Moreno, 1925, 9) y Richmond (Richmond, 1931, 90-1), sin llegar a estudiarlo directamente, al segundo cuarto del siglo III. Los autores posteriores han seguido sin discusión esta cronología (Balil, 1960, 192). A diferencia de la mayor parte de los recintos amurallados hispanos, no ha sido objeto de una descripción detallada. Tan sólo algunos trabajos de Luengo (Luengo, 1962) y, especialmente, de Mañanes (Mañanes, 1976; 1982; 1983; 1984) proporcionan algunas noticias sobre el tema. En 197172 , este último autor realiza excavaciones en el lienzo septentrional de la muralla, sobre cuyos 
resultados, publicados en 1985 (Mañanes, 1985), nos pronunciaremos más adelante.

La ciudad romana se extendía por una superficie de unas 27 has., ocupando una mesetilla de forma trapezoidal circundada por un perímetro amurallado de unos 2100 metros (Mañanes, 1976, 81). Las torres, cuya filiación romana no parece probable, son de planta semicircular, de unos 7 metros de diámetro y separadas por cortinas de 12 a 14 metros. Luengo informa sobre la existencia de un lienzo unido a una gran torre cuadrada realizada con grandes sillares detrás del convento de San Francisco, que fue enterrada o destruida al reformar esta parte de muralla (Luengo, 1962, 155). En el recinto no se conserva ninguna puerta original.

El aparejo de la muralla romana plantea numerosos problemas. Gómez-Moreno interpretó como pertenecientes a la muralla romana unos restos situados a la izquierda de la actual puerta del Sol, realizados con lajas pizarrosas y mortero muy duro (Gómez-Moreno, 1925, 9). Por su parte, Luengo, a partir de un fragmento visible en el lugar conocido como "La Brecha", opinaba que el material constructivo era la sillería con núcleo interno de hormigón (Luengo, 1962, 155). El paramento actual de la muralla, claramente medieval, esta revestido con sillarejo pizarroso mal trabado, en el que abundan los materiales romanos reutilizados. Su relleno se realiza a base de piedras con tierra y cal (Mañanes, 1983, 31).

La excavación practicada por Mañanes en la brecha abierta en la muralla durante la Guerra de la Independencia puso al descubierto datos de excepcional importancia para el conocimiento del recinto. Por primera vez se constató la existencia de un nivel fundacional romano en la muralla. Los trabajos arqueológicos revelaron la existencia de dos torreones semicirculares de 8 metros de diámetro realizados con sillares de granito, que flanqueaban una puerta. Sobre la torre este apoyaba directamente un muro de 3,7 metros de anchura, con un paramento externo de opus incertum y núcleo de hormigón muy duro de color ocre claro. Este muro estaba embutido dentro de la muralla medieval, que mide unos 5, 30 metros de espesor (Mañanez, 1976, 81-2; Mañanes, 1985, 209-11). Respecto a la cronología de la muralla de 3, 70 metros, Mañanes afirma en un determinado momento que "..si ella no es romana, sino altomedieval, esté situada encima de la romana, ya que si comparamos esta anchura con otras murallas del Imperio, es bastante similar" (Mañanes, 1985, 211). La confusa interpretación de Mañanes no permite dilucidar si este autor se inclina por una fecha de construcción bajoimperial o altomedieval, aunque en otros lugares apunta esta última posibilidad (Mañanes, 1983, 28-30; Mañanes, 1985, 209). la ausencia de estratigrafías tampoco contribuye a clarificar el panorama. Por otra parte, en otros trabajos Mañanes ha seguido manteniendo que la ciudad tuvo un recinto bajoimperial edificado a raiz de las invasiones franco-alamanas (Mañanes, 1976, 80).

En síntesis, la excavación de Mañanes, que plantea importantes dudas metodológicas, deja sin respuesta cuestiones básicas acerca de la datación del recinto. Las excavaciones llevadas a cabo de 1992 en un solar intramuros y colindante con la muralla, ha permitido comprobar que ésta parece edificarse de una sola vez. Constituye una obra imponente, de unos 6 metros de anchura, cuyos cimientos alcanzaron los 6 metros de profundidad desde el arranque superior de la zapata. Conserva cerca de 6 metros de alzado. La fortificación amortiza estructuras altoimperiales por lo que su dotación es, inequívocamente, bajoimperial. La publicación de este hallazgo debe aportar datos más completos sobre este tema. (4). Quedan sin resolver las dudas sobre la existencia de un recinto

(4) Agradecemos a V. García Marcos esta información inédita. 
altoimperial de origen castrense, considerado por algunos autores como la razón misma de la existencia de la antigua Asturica (Schulten, 1943, 129; Luengo, 1962, 162; Balil, 1965, 282; Mañanes, 1976, 77-8 entre otros) y cuyos restos pudieran corresponder a la puerta descubierta por Mañanes. En cualquier caso ha quedado suficientemente aclarado el origen romano del recinto amurallado de Astorga.

No es preciso hacer aquí hincapié en que el empleo de materiales reutilizados en estructuras defensivas como fecha post quem para su erección, no resulta hoy en día un criterio válido para realizar atribuciones de tipo cronológico acerca de las mismas.

\section{Bergidum Flavium}

En el llamado Castro Ventosa, situado en un cerro junto a la antigua Bergidum Flavium (Cacabelas) se ha identificado recientemente una muralla romana cuyas características constructivas apuntan al período tardoromano y guardan esa gran semejanza con otros recintos fortificados de la región. Las pequeñas catas arqueológicas redactadas por I Vidal (a quien damos las gracias por esta información) parecen confirmar esta cronología, pero es imprescindible realizar un estudio más detallado antes de pronunciarse al respecto.

\section{Gijón}

En 1982, durante la realización de una excavaciones de urgencia en el casco antiguo de la ciudad de Gijón, correspondiente al actual barrio de Cimadevilla, se localizaron los restos de una fortificación, cuya ubicación correspondía con las noticias de los eruditos locales, que hablaban de un castra stativa de época de Augusto (Somoza, 1908). Por otra parte, las fuentes medievales recogen la existencia de una "cerca", derruida a finales del siglo XIV.

A partir del hallazgo de la muralla romana, las campañas arqueológicas, dirigidas por uno de nosotros -C. Fernández Ochoa-, se han sucedido sin interrupción hasta la fecha. Los resultados de las mismas se han ido dando a conocer a través de distintos trabajos, que han puesto de manifiesto las características constructivas de un recinto amurallado bajoimperial completamente desconocido hasta 1982 y que hoy en día se encuentra entre los mejor constatados arqueologicamente (entre otros: Fernández Ochoa, 1983; Fernández Ochoa y VV. AA., 1984; Fernández Ochoa, 1986; Fernández Ochoa y Martínez Díaz, 1986-7; Alonso Sánchez y Fernández Ochoa, 1988; Fernández Ochoa, 1992 a; Fernández Ochoa, 1992 b). La Memoria definitiva, pendiente de los últimos sondeos en distintos lugares del perímetro, se encuentra en proceso de elaboración.

La muralla formaba un circuito lineal de planta irregular, adaptado a la topografía del terreno, que miraba hacia el interior, dejando el mar a su espalda. Su perímetro es de unos 850 metros y abarcaba una superficie de unas 16 has., correspondiente al Cerro de Santa Catalina, encerrando en su interior a la mayor parte del barrio de Cimadevilla. La línea de la fortificación se ha comprobado en las áreas central y oriental del istmo. Recientemente, los sondeos realizados es al sector accidental, hasta ahora infructuosas, han permitido localizar la estructura, aunque ésta parece estar muy arrasada.

La muralla de Cimadevilla estaba flanqueada por torres semicirculares, ligeramente peraltadas, de unos 4, 60 a 5 metros de diámetro, que sobresalen del lienzo unos 3, 30 metros. Los cubos se situaban a intervalos de 18 metros. Durante los trabajos de excavación se han docu- 
mentado cinco torres, pero se puede aceptar con seguridad la existencia de otras como la de la zona del Club de Regatas, en el extremo oriental del Cerro.

Durante el verano de 1988 se hallaron los restos de la puerta principal de la ciudad romana en el entorno de la llamada Torre del Reioj y de la calle Recoletas, precisamente donde se ubicaba la antigua entrada de la villa. La puerta estaba flanqueada por dos torreones cuadrangulares, de 5, 40 metros de lado, que tal vez fueron macizos en su base. La anchura de la entrada es de unos 7, 50 metros. Los restos de la cimentación y el alzado permiten suponer una puerta de doble arco, retranqueada respecto a la linea de la muralla para facilitar su defensa, dado que las puertas eran los puntos más débiles del sistema defensivo.

Por lo que se refiere a técnica edilicia, la muralla de Gijón se ajusta al modelo de doble paramento con relleno interior de opus caementicium compuesto por piedras calizas de tamaño variado a base de tongadas regulares. Los paños del lienzo presentan variantes en la cara extramuros donde hallamos sillares de arenisca de gran tamaño -algunos con huellas de unión a base de grapas en forma de "cola de milano" y paramentos de sillarejo de arenisca bien escuadrado y careado, unido con argamasa. La cara interna se configura a base de mampuestos de caliza y algunas areniscas irregulares. El espesor del muro es 4,60 metros, medida que se mantiene constante a lo largo de todo el trazado. La altura máxima conservada es de 1, 80 metros.

La fosa de cimentación se talló en la roca madre o en la arcilla natural, con una profundidad variable según la topografía de cada zona, aunque en ningún caso sobrepasa los 1, 40 metros. La zapata se realiza por medio de hiladas sucesivas de mortero rico en cal y arena, compactado con piedras pequeñas y cantos rodados.

La cronología de esta estructura defensiva plantea algunas incógnitas de difícil respuesta. El sistema de grapas utilizado en los sillares de las torres de flanqueo de la puerta, bien documentado en construcciones altoimperiales de Tarraco, Emerita o Italica, pero poco empleado en edificios tardíos, podría inclinarnos a pensar que la muralla pudiera tener una fase altoimperial sobre la que se levantó posteriormente la construcción tardía. Sin embargo, nada en los resultados de las excavaciones lleva a confirmar esta hipótesis. El sistema constructivo es idéntico en todos los puntos del recinto, y no se observan huellas de recrecimiento de muros. Por otra parte, aunque los sillares de las torres de flanqueo de la puerta son reutilizados, las grapas se hicieron especificamente para la obra de la muralla, puesto que traban perfectamente un sillar con otro, adaptando incluso los tamaños según las dimensiones de cada piedra.

Las comprobaciones obtenidas en los sondeos estratigráficos, señalan la construcción de la muralla en una fecha post quem al siglo II d. C. Por otra parte los materiales de los siglos IV-V son muy abundantes (Alonso Sánchez y Fernández Ochoa, 1988). Estos datos llevan a situar la construcción de la muralla en un momento tardorromano, a finales del siglo III o comienzos del siglo IV, al que parece corresponder la obra completa, si bien, al tratarse de una datación post quem, hay que dejar margen a un posible retraso de esta fecha.

La muralla bajoimperial de Gijón es una de las mejor documentadas arqueologicamente en los últimos años, aunque en su conocimiento se revelan algunas carencias propias de las dificultades de la excavación y de la ausencia de estratigrafías, entre las cuales destaca la imposibilidad de ofrecer una datación más ajustada que el simple terminus post quem. Otra cuestión recientemente aclarada es la relación estructural entre la muralla y las Termas de Campo Valdés, que quedan incluidas dentro del circuito amurallado, mientras que el trazado del recinto en el sector occidental de Cimadevilla aún presenta bastantes incógnitas. 


\section{APÉNDICE: Turres y Castella}

No es este el lugar para pronunciarnos acerca de las fortificaciones del tipo turres o castella, cuyas menores dimensiones desmienten un carácter urbano. Algunos autores han mantenido que en época bajoimperial estas fortalezas menores desempeñaron un importante papel en la defensa de nudos de comunicación e incluso de pretendidos limes hispanicos. Recintos de este tipo se han querido ver en el Valle del Duero (Taracena, 1924-5; Wattemberg, 1961-2; Maluquer de Motes, 1968), en la Lusitania (Taracena, 1949, 439; Alonso Sánchez, 1988) y en la zona pirenaica (Pita Mercé, 1967; Lara Peinado, 1973, 47-9 y 78-80). Sin embargo, su pretendida cronología tardorromana es tan discutible como la misión que se les ha atribuido tradicionalmente, tal y como ha puesto de relieve Fuentes Domínguez en el caso de la Submeseta norte (1988) (5). Lo mismo podemos decir acerca de algunas fortalezas como las de Puig Rom o Montefrío, interpretadas como visigodas a pesar de sus innegables paralelos tipológicos con el mundo tardorromano (Palol, 1952; Olmo Enciso, 1985).

\section{ESTUDIO Y VALORACION}

El catálogo que aquí presentamos revela la existencia de una ingente bibliografía que, de una u otra manera, alude a los recintos amurallados bajoimperiales. Sin embargo tan sólo contamos con dos monografías completas sobre murallas hispanas de este periodo: los estudios de Balil sobre la colonia Barcino y los de Arias Vilas acerca de Lucus Augusti. Esto no es obstáculo para que, gracias a numerosas publicaciones más específicas y de menor extensión, nuestro conocimiento sobre otros yacimientos como Tiermes, Gijón o Gerunda sea tan completo, e incluso más, que el de las primeras. Restaría un amplio capítulo de referencias bibliográficas de menor envergadura, que restringen nuestras posibilidades interpretativas en la mayor parte de los casos al mínimo.

De una primera lectura del catálogo de fortificaciones urbanas que aquí presentamos se desprende la imposibilidad de considerar muchos de estos recintos como edificados en época tardía. Hemos abordado el análisis de un total de 43 núcleos urbanos que presumiblemente dispusieron de murallas en época bajoimperial. De una relación tan amplia debemos descartar aquellas cuya existencia no está suficientemente constratada desde el punto de vista arqueológico -al menos a la vista de lo que de ellas se ha publicado hasta la fecha-, caso de Ampurias, Ilerda, Sós del Rey Católico, Pompaelo, Calagurris, Carthago Nova, Ilici, Begastri, Castulo, Toletum, Uxama, Clunia, Cappara, Augustobriga, Aeminium, Bracara Augusta y Aquae Flaviae. Tampoco podemos considerar aquellas murallas en su momento erróneamente interpretadas como bajoimperiales, entre las que contariamos las de Ologitum, Cantabria, Abela, Ilipa Magna, Mulva y Belo.

Parece llegado el momento de poner fin a aventuradas atribuciones de carácter exclusivamente tipológico ya que, mientras no exista una comprobación basada en registros arqueológicos precisos, no podremos incluir determinados casos dentro de la nómina de fortificaciones urbanas tardoimperiales. Estos serían los de Caurium e Idanha-a-Velha, en los que hasta el momento no se han acometido excavaciones metodológicas.

(5) La bibliografia fundamental acerca del pretendido Limes bajoimperial del Valle del Duero puede encontrarse en el mencionado trabajo de A. Fuentes Domínguez (Fuentes Domínguez, 1988) o, más completa, en la Tesis Doctoral del mismo autor (Fuentes Domínguez, 1989). 
En consecuencia, en el estado actual de la investigación, tan sólo se pueden considerar murallas bajoimperiales con cierta garantía un conjunto de 17 recintos: Barcino, Gerunda, Caesaraugusta, Inestrillas, Iruña, Monte Cildá, Pollentia, Tiermes, Italica, Emerita Augusta, Ebora, Norba, Conimbriga, Lucus Augusti, Castra Legionis VII Geminae, Asturica Augusta y Gijón. Las fortificaciones urbanas de Asturica y Norba nos planteaban ciertas dudas sobre la conveniencia de incluirlos entre recintos con datación más ajustada. Sin embargo, en ambos se han constatado murallas de origen romano -bien es verdad que de cronología imprecisa-, que presentan numerosas lápidas reutilizadas en sus paramentos y perduran como fortificaciones de primer orden durante la Edad Media, lo que, a nuestro juicio, constituye un argumento de cierto peso. En el caso de Astorga, los recientes descubrimientos despejan definitivamente la duda sobre la existencia de un recinto tardorromano. Algo más problemático es el caso de Inestrillas, datado por el hallazgo de una lápida del siglo II embutida en la muralla, aunque el aparente abandono de este yacimiento desde época tardorromana hasta nuestros días, avala la atribución bajoimperial. Por lo que respecta a Ebora, aceptamos la cronología propuesta por V. Correia a pesar de que los resultados de las excavaciones no han salido a la luz, pero el desconocimiento de las características constructivas del recinto bajoimperial, nos impide incluir éste en el estudio de conjunto que abordaremos a continuación. Situación semejante es la de Bracara Augusta, donde todos los datos apuntan a una datación bajoimperial, pero cuyas excavaciones no han sido capaces de proporcionar una fecha post quem. También en este caso hemos preferido no incluirla.

Estos 17 recintos -exceptuando Ebora y Bracara-serán los que tengamos en cuenta a la hora de acometer el análisis de las características de este periodo.

\section{Contexto urbanístico de las murallas bajoimperiales}

Uno de los aspectos que mayor polémica ha generado en la investigación sobre recintos tardíos ha sido la imbricación de éstos dentro del proceso general de la configuración urbana en la ciudad hispanorromana. Los datos disponibles en la actualidad permiten agrupar las fortificaciones de este periodo en varios grupos de acuerdo con su origen:

\section{Murallas que reutilizan trazados defensivos anteriores}

a) Sobre trazados indígenas Inestrillas

b) Sobre recintos altoimperiales

Barcino

Gerunda $\left(^{*}\right)$

Caesaraugusta

Emerita Augusta

Castra Legionis VII Geminae (*)

\section{Murallas de nueva planta}

Iruña

Monte Cildá

Pollentia

Tiermes

Gijón

Lucus Augusti 
3. Murallas que rectifican perimetros urbanos altoimperiales

Italica

Conimbriga

\section{Recintos de fundación romana imprecisa \\ Asturica Augusta \\ Norba \\ Ebora}

A la vista de estas modalidades de edificación, no parecen existir diferencias significativas entre las murallas bajoimperiales hispanas y sus homólogas gálicas. En el caso hispano no parece defendible la supuesta reducción generalizada del perímetro urbano, tópico consagrado entre historiadores y arqueólogos hasta hace pocos años. Tan sólo los casos de Conimbriga y, posiblemente, Italica, parecen responder a una contracción del hábitat urbano intramuros por motivos específicos aún no bien definidos y no necesariamente coincidentes. El resto de los recintos hispánicos se distribuyen a partes casi iguales entre los que, hasta el momento, pueden considerarse de nueva planta -Tiermes, Lucus, Gijón, Iruña, Pollentia y Monte Cildá- y los que refuerzan las antiguas estructuras defensivas de origen anterior, indígenas -Inestrillas- o altoimperiales - Barcino, Caesaraugusta y Emerita-. A estos tres últimos casos habría que sumarles las murallas de Gerunda, levantadas en época tardorrepublicana, y las del campamento de la Legio VII en León, donde se documenta un primer recinto que García y Bellido clasífico sin argumentos estratigráficos como obra de finales del siglo III d. C. Caso que merece un comentario específico es el de Tarraco, que no hemos incluido entre los recintos de este periodo, donde la perduración la la fortificación republicana durante toda la presencia romana parece fuera de toda duda.

En el estado actual de la investigación resulta imposible pronunciarse sobre el origen de los recintos de Asturica, Ebora y Norba. Las investigaciones sobre ellos resultan demasiado confusas o aún no han sido publicadas.

\section{Topografia y extensión de los recintos amurallados}

Muy vinculado al apartado anterior se encuentra el del trazado y extensión de los recintos amurallados. Las fortificaciones de nueva planta adoptan en todos los casos formas irregulares, adaptadas a las características topográficas del terreno. Esta misma situación se encuentran también algunas murallas edificadas sobre obras defensivas anteriores -Inestrillas, Gerunda o Emerita-. No debe llamar la atención esta comportamiento, que entra dentro de la costumbre habitual seguida en el trazado de las ciudades hispanorromanas de cualquier época. Tan sólo en recintos de origen augusteo -Barcino, Caesaragusta- la muralla tardía mantiene la regularidad fundacional. A ellos habría que añadir el caso específico de León, cuya planta responde al tipo consagrado de campamento romano imperial.

Conimbriga ha sido la única ciudad en la que se ha documentado la integración de un edificio público -en concreto un compejo termal- dentro del trazado general defensivo. La relación de la muralla emeritense con el espacio del anfiteatro, aún está por resolver.

En cuanto a la extensión, despejada las dudas sobre la reducción de los perímetros, las cifras oscilan entre las 5-6 has. de Gerunda y las 60 de Caesaraugusta, aunque la mayoría de los recintos se concentran en torno a dos grupos bastante bien definidos: los asentamientos de extensión media, entre 9 y 12 has. -Barcino, Monte Cildá, Iruña, Inestrillas, Conimbriga-, en algunos de 
los cuales albergamos serias dudas acerca de su carácter especificamente urbano -Inestrillas o Monte Cildá-; las ciudades de notables dimensiones -entre 16 y 28 has.- concentrados en el Noroeste peninsular -Lucus, Asturica, Castra Legonis VII Gemina y Gijón-, a los que habría que añadir Tiermes. No disponemos de datos acerca del perímetro de la Emerita tardorromana, que suponemos respetable, así como de Pollentia o Italica.

A la vista de estos datos numéricos no hay constancia de un interés específico por amurallar ciudades de un determinado tamaño, que pudiera dar alguna pista sobre la existencia de alguna finalidad o programa estratégico concreto. No es este el lugar para pronunciarnos acerca de la posible existencia de fortificaciones menores del tipo turres o castella en época tardía. La validez de la atribución bajoimperial de algunos de estos recintos ha sido cuestionada de forma contundente (Fuentes, 1988).

\section{Estructura de las murallas. Las posibilidades de una tipología}

La estructura de las murallas tardorromanas hispánicas se configura, al igual que todas las de este periodo, mediante dos paramentos exteriores y un relleno interno de opus caementicium. El estudio de la técnica edilicia nos permite afirmar que, en la mayoría de las ocasiones, los paramentos de sillería trabajada a la manera del opus quadratum predominan en la cara externa de los muros. Esta técnica arquitectónica se emplea en los recintos de Barcino, Gerunda, Caesaraugusta, Monte Cildá, Iruña, Tiermes, Emérita, Norba, Lucus, Conimbriga y Gijón. En estos tres últimos casos su uso se circunscribe a la zona de las puertas. Desconocemos si éste fue el material constructivo de otros recintos de la zona astur como Asturica y Castra Legionis VII. Evidentemente, en Hispania, la facilidad de obtención de piedra de buena calidad explicaría esta característica constructiva. En todos los casos se documenta el empleo de piedra local o traida de canteras próximas.

Dentro de esta aparente uniformidad técnica se observan notables variantes desde el punto de vista de las dimensiones de los sillares, de la calidad de la talla, de su acabado o del sistema de trabazón de éstos entre si. En la mayor parte de las ocasiones la unión se realiza a hueso, aunque se ha documentado el empleo de argamasa -Caesaraugusta, Gijón, Inestrillas- e incluso, a partir de la impronta dejada en la piedra, parece comprobarse la utilización de grapas metálicas "en cola de milano" -Gijón y Tiermes-. La colocación de sillares "a soga y tizón" es bastante común.

Entre los sillares empleados en el paramento de la muralla son muy abundantes los materiales epigráficos y arquitectónicos procedentes de edificios amortizados pertenecientes a épocas anteriores. Esta práctica se atestigua asímismo en el relleno de la obra. Sin embargo, como ya bien apuntó Balil, estos materiales representan un mínimo porcentaje en la estructura de la muralla (Balil, 1961, 104-5).

La técnica de opus vitatum solamente se documenta en la muralla de Conimbriga, cuya construcción manifiesta cierta perfección técnica. En el sector occidental de Iruña y en los recintos de Lucus, Gijón y Monte Cildá se empleó el sillarejo, trabajado de diferentes maneras.

Se pueden anotar algunos casos de dualidad técnica en cuanto a la estructura del paramento. Este sería el caso de Gerunda, que emplea la muralla "ciclópea" tardorrepublicana como zócalo. En Gijón hemos podido constatar la coexistencia de tres tipos distintos de paramentos dentro de un único momento constructivo. Esta solución aplicada en la muralla gijonesa puede tal vez proporcionar nuevas pistas acerca de la configuración estructural de otros recintos de la Gallaecia -Asturica, Lucus, Castra Legionis VII Geminae-, hasta ahora objeto de una amplia contro- 
versia sobre el paramento original de su fase tardorromana. Este comentario no se puede hacer extensible al caso de Iruña, donde los datos disponibles parecen apuntar dos momentos o proyectos constructivos distintos.

Los paramentos internos han estado más expuestos a las agresiones propias de la continuidad de la vida urbana en asentamientos de muy larga ocupación, y de ahí que sean bastante menos conocidos. Los pocos conservados parecen indicar una mayor regularidad en cuanto al tamaño y disposición del aparejo empleado -un simple sillarejo en la mayor parte de los casos- a cambio de una apariencia menos monumental que las cortinas exteriores.

El relleno interno que liga ambos muros es casi siempre el opus caementicum, en alguna ocasión -sería el caso de Conimbriga- de una excelente calidad. En Inestrillas, Caesaraugusta y Emerita, el hormigón deja paso a un simple núcleo de piedras de distintos tamaños unidas con tierra. Ambos tipos de relleno conviven simultaneamente en distintos segmentos de las murallas de Gerunda y Lucus Augusti.

El espesor de los lienzos es siempre superior a los tres metros, medida ésta de la fortificación de Inestrillas. El resto oscila entre los 3 y 5 metros de anchura. Por encima de esta cifra sólo se encuentran las murallas de Legio VII, Iruña y Caesaraugusta, que proporciona la desmesurada dimensión de 6, 42 metros. Estas medidas, con la posible excepción de Caesaraugusta, no se apartan de lo que suele ser habitual en los recintos occidentales de este momento (Johnson, 1983, 37).

Debido al arrasamiento de los recintos tardíos es casi imposible hablar de cifras siquiera aproximadas sobre la altura de lienzos y torres. Los perímetros amurallados de Lucus y Barcino permiten intuir que alcanzaban los 10 metros de alzado, posiblemente superando incluso estas cifras, lo que se acercaría a los cálculos realizados para las murallas galas (Bedon, Chevalier y Pinon, 1988, 108). No cabe duda que las torres se alzaban varios metros por encima del camino de ronda.

Respecto a la cimentación, aunque todas las murallas debieron poseer estructuras de este tipo, sólo han podido ser constatadas en Barcino, Gerunda, Legio, Astorga, Gijón y Lucus Augusti. En todas ellas los cimientos se asientan con una mínima preparación del terreno, sin alcanzar excesiva profundidad. La única excepción es Astorga, donde se hunden 6 metros desde el arranque superior de la zapata. El material constructivo empleado en los fundamentos documentados se compone de cantos y piedras de distinto tipo y tamaño con una ligera argamasa, con el fin de facilitar el drenaje de la estructura. En la parte inferior de las murallas de Barcino, Tiermes, Norba, Astorga, Gijón y Castra Legionis VII se aprecia una banqueta o zarpa de fundación. Los casos de Tiermes y Gijón nos llevan a pensar que no existían normas fijas para la construcción de banquetas fundacionales, sino que éstas debían aparecer cuando las características geológicas y topográficas del terreno así lo requerían.

Con los escasísimos datos disponibles no podemos documentar una búsqueda estética en el acabado de las fortificaciones hispanas semejante al de las murallas galas.

Todos los recintos hispánicos con posibilidad de asignarse al periodo bajoimperial presentan, sin excepción, torres proyectadas al exterior. Como es bien sabido, las torres constituyen uno de los atributos más significativos de las fortificaciones tardorromanas, tanto militares, como civiles. Sin embargo, a la vista de los que conocemos, no se puede mantener la opinión aceptada de forma general de que las torres semicirculares eran las más frecuentes en las fortificaciones hispanas (Balil, 1961, 115-6). Las formas, dimensiones y posiciones de las torres presentan una gran variedad, no sólo en Hispania, sino también en otras provincias occidentales (Bedon, Chevalier 
y Pinon, 1988, 110). En el caso hispano, el número de murallas reforzadas con torres cuadrangulares es practicamente idéntico a los que presentan cubos semicirculares. Entre las primeras se encuentran Barcino, Gerunda, Iruña, Monte Cildá, Conimbriga y tal vez Asturica y Norba. Las torres semicirculares se documentan en Caesaraugusta, Inestrillas, Iruña, Tiermes, Emerita, Lucus, Legio VII y Gijón. Resulta bien conocida la existencia de una torre poligonal en el ángulo noroeste de la fortificación barcelonesa, a la que no podemos añadir hasta el momento ninguna otra de las mismas características. Las torres de planta circular de la muralla de Gerunda plantean numerosos problemas de atribución cronológica. Barcino es el único recinto en el que se documentan torres circulares angulares, con la excepción, aún sin comprobar, de Norba. Con la información disponible hasta el momento no podemos pronunciarnos sobre la aparente coexistencia de torres semicirculares y cuadradas en las murallas de Asturica Augusta. El hallazgo de un torreón de este último tipo en las murallas de la capital asturicense podríamos tal vez ponerlo en relación con alguna puerta de la ciudad. El caso de Iruña requiere un análisis más detallado de sus momentos constructivos.

Respecto a las medidas de las torres, no puede constatarse una regularidad. Las torres semicirculares de mayores dimensiones se encuentran en Lucus Augusti -13, 40 metros-. Gijón, con 4, 60 a 5 metros, y Tiermes, con 4,5 metros presentan los modulos más pequeños y semejantes. Las torres cuadrangulares se mueven entre los 5,30 a 6 metros de frente en Barcino y los 6, 20 metros de la Torre Gironella de Gerunda. Esta aparente similitud en las medidas de los torreones cuadrangulares puede tener una correspondencia en Conimbriga, Iruña y Asturica, que también tuvieron torres cuadradas. La irregularidad se manifiesta asímismo dentro del mismo recinto.

Tampoco se comprueba una norma fija en las distancias que separan las torres. Estas son, sin duda, más reducidas que las altoimperiales, pero existe una gran fluctuación en los intervalos de una a otra muralla y, dentro de un mismo recinto, de un lienzo a otro. Los valores nunca superan los 20 metros, excepto en el caso de Inestrillas, que alcanza los 24 metros. Los ejemplos de ritmo más regular son las murallas de Gijón -6 a 10 metros-, Castra Legionis VII Geminae -9 metros-, Barcino - 6 a 10 metros- y Caesaraugusta -13 a 14 metros-. La variación de las distancias entre las torres debe tener alguna relación con la topografía concreta de los espacios a defender. En las zonas más debiles del recinto, las torres se multiplicarían. En este capítulo concreto de la separación entre torres sí parecen existir diferencias significativas entre las murallas hispanas y las del resto de la pars occidentalis del Imperio (Richmond, 1931, 98). Balil lo considera una peculiaridad peninsular, donde se acenturía la tendencia generalizada a la multiplicación de torres registrada en el resto del Imperio (Balil, 1961, 108). Para algunos autores esta propensión tardorromana a la reducción de los lienzos entre torres responde a razones de táctica militar. El fin perseguido sería reducir el número de ángulos muertos de las torres y facilitar el despliegue de la maquinaria de guerra, sea ésta ballestas o ballistae (Balil, 1961, 109).

Las puertas, por su carácter de zona de paso, mantenido a lo largo de los siglos, son los elementos de la estructura defensiva que más dificilmente han llegado hasta nosotros. Unas veces porque han sido derribadas para facilitar el crecimiento urbano; otras porque han sufrido repetidas remodelaciones. Se han conservado un reducido número de ellas que, aún así, resulta suficiente para documentar su estructura original. El estudio de las puertas de las murallas hispanas elaborado por Alonso Sánchez no discrimina entre la topografía y la atribución cronológica de los recintos, puesto que incluye murallas tan cuestionadas para la época bajoimperial como las de Ilerda o Caurium (Alonso Sánchez, 1983, 53 y 56). Tampoco creemos ajustada a la realidad 
la existencia mantenida por esta autora y de torres poligonales de flanqueo en los recintos de Carmona y Barcelona, hipótesis totalmente superada en los estudios más recientes (Alonso Sánchez, 1983, 57).

Todos los accesos de los recintos amurallados hispános responden a un esquema general muy sencillo, consistente en una puerta estrecha con un solo vano y pasadizo flanqueado por dos torres en resalte al exterior. Las únicas excepciones son la Puerta Decumana de Barcino, con tres vanos, de origen altoimperial (Granados, 1977-8) y la puerta de entrada al recinto gijonés, que presenta un doble arco apoyado en un pilar central (Fernández Ochoa, 1992 a, 158). Según la reconstrucción propuesta para la "Porta de Regomir" de Barcino, ésta sería muy semejante a la de Gijón (Pallarés, 1969, 27-9).

Las torres de flanqueo son de planta semicircular o cuadrangular. En las fortificaciones hispanas conviven ambos tipos de torres en idéntica proporción. Puertas con cubos de flanqueo semicirculares se encuentran en Inestrillas, Iruña, Lucus y Asturica, mientras que en Gerunda, Gijón, Monte Cildá y Conimbriga ostentan torres cuadrangulares. Todas ellas están edificadas en opus quadratum, lo que indica una atención prioritaria hacia este sector del recinto murado.

A la vista de lo que conocemos sobre murallas hispanas, podemos suscribir perfectamente la afirmación de Johnson en el sentido que no se puede aceptar la correspondencia entre torres cuadradas y recintos militares y torres semicirculares y recintos civiles (Johnson, 1983, 50). El empleo de uno u otro tipo de torre habría que atribuirlo a un gusto, moda o programa específico para cada caso o cada momento.

En algunos casos no hay que descartar que la morfología de la puerta tenga alguna correspondencia con el diseño anterior de la misma. Buen ejemplo de esta reutilización sería la puerta Decumana de Barcino.

Siguiendo una tendencia generalizada y suficientemente contrastada para el Bajo Imperio, en la inmensa mayoría de las murallas romanas de Hispania no hay huellas de poternas. Tan sólo se ha documentado una en Iruña.

Conocemos muy poco acerca de otros elementos constructivos pertenecientes a la estructura de las murallas bajoimperiales. El arrasamiento generalizado de su parte alta impide conocer en profundidad detalles de tanta trascendencia como el sistema de cubrición de las torres o la posible existencia de parapetos almenados. El camino de ronda se conserva en Barcino y tal vez en Lucus, aunque no podemos pronunciarnos sobre si las alteraciones medievales han podido enmascarar su estructura original. Resulta muy confusa la interpretación del camino de ronda en Monte Cildá. Por otra parte, se han identificado restos de seis escaleras interiores en las murallas lucenses y se mantiene la posibilidad de una escalera exterior de acceso a la parte superior de la muralla de Barcino.

A la vista de la enorme disparidad existente tanto en la estructura, como en la edilicia de las murallas bajoimperiales hispanas, no podemos aceptar estas características como un criterio de clasificación válido para este tipo de recintos. De ahí que al comienzo de este análisis hayamos prescindido de algunas fortificaciones urbanas, tradicionalmente contempladas por la investigación como pertenecientes a este periodo. La atribución bajoimperial de recintos como Caurium o Idanha-a-Velha se ha basado exclusivamente en sus semejanzas construcivas con otros mejor documentados.

Balil, en los inicios de su investigación sobre defensas hispanas tardoimperiales, agrupó las murallas urbanas en dos estilos constructivos diferentes y correlativos: las llamadas fortificacio- 
nes de "estilo legionario hispánico", cuyas características principales fueron definidas por Richmond en su día (Richmond, 1931), que se concentran en el Noroeste peninsular -Castra Legionis VII Geminae, Lucus Augusti y Asturica Augusta-, a las que añade Caesaraugusta; los recintos derivados de la primera fase de las Murallas Aurelianas de Roma, donde incluyó Barcino y Caurium (Balil, 1960, 196-7; Balil, 1961, 129). A las murallas "legionarias" les atribuye una cronología algo anterior al primer momento constructivo de las Murallas Aurelianas, que inspiraron, según este autor, la edificación de los recintos de Caurium y Barcino. Estos, por lo tanto, serían algo más tardíos.

Con los datos disponibles en la actualidad no parece adecuado seguir manteniendo esta dicotomía tipológica. Las murallas hispanas responden a la misma diversidad estructural que se aprecia en el resto del Imperio. Incluso, la única peculiaridad constructiva de las murallas hispanas -el acercamiento entre torres- se documenta tanto en los recintos supuestamente legionarios como en los basados en modelos itálicos. La existencia de cierto "aire de familia" entre los recintos del Noroeste peninsular habría que interpretarla, más que como un estilo constructivo propio de la región, como una aplicación específica de modelos vigentes en otros puntos del Imperio, probablemente vinculada a la fuerte implantación militar en la zona. Habría que matizar por lo tanto el significado del llamado "estilo legionario hispánico" de Richmond, ya que carecemos hasta el momento de argumentos contundentes sobre el papel desempeñado por el ejército en la erección de estos perímetros amurallados. En este sentido habría que señalar la dificultad para deslindar entre el carácter militar y el carácter civil de buena parte de los núcleos urbanos bajoimperiales. Del grupo definido por Richmond originalmente habría que desgajar Caesaraugusta, incluida apriorísticamente por analogías no del todo compartidas. Como veremos más adelante, ningún elemento de juicio nos anima a datar este conjunto regional en un momento cronológico anterior al de otros recintos.

Por otra parte no existe ninguna razón para dudar de la existencia de influencias itálicas en la construcción de alguno o varios de los recintos bajoimperiales. Que en determinadas casos, como el de Barcino, éstas fueran más potentes, tampoco es un hecho que deba llamarnos especialemente la atención.

\section{La cronología de los recintos hispánicos tardíos}

Para Hispania carecemos de fuentes literarias o epigráficas que testimonien la construcción o reparación de recintos amurallados tardíos. La única referencia escrita es la problemática descripción de Pompaelo (Arce, 1982, 97). En ningún caso se ha documentado la intervención imperial directa en cuestiones de estrategia defensiva peninsular. Este hecho estaría justificado por la posición de retaguardia de la Península Ibérica respecto a las áreas más amenazadas del Imperio. A pesar de ello, Hispania se vió inmersa en el ambiente de amurallamiento generalizado del periodo tardorromano, fenónemo del que sólo han llegado hasta nosotros testimonios arqueológicos.

El momento de edificación de las murallas bajoimperiales hispanas es todavía bastante impreciso. Los 17 recintos que hemos considerado con cierta seguridad de este momento proporcionan fechas aproximadas, basadas en la amortización de estructuras claramente anteriores o en la comprobación arqueológica de su uso durante el periodo tardorromano. Estos argumentos sólo pueden llevarnos a establecer dataciones post quem más o menos ajustadas. De hecho, las 
investigaciones realizadas en los últimos años unicamente han podido establecer que el comienzo del amurallamiento en la Península Ibérica arranca aproximadamente del $260 \mathrm{~d}$. C., extendiendose hasta un momento impreciso. El caso de Gerunda, sin duda el recinto mejor constatado arqueologicamente de todos los peninsulares, quizá sea el que mejor ejemplifica la extremada dificultad de obtener registros de época que permitan asignar una fecha exacta a la construcción de una muralla. La carencia de fosas de fundación, el empleo de materiales de muy larga cronología y la continuidad del asentamiento urbano en el mismo lugar durante siglos produce cierto pesimismo sobre la posibilidad real de llegar a datar estas construcciones dentro de unos límites cronológicos más precisos.

El problema de la datación post quem p̉odría resumirse en que, aunque resulta orientativa respecto a fases cronológicas amplias, no permite discernir dentro de ellas periodos más cortos. Por ello el panorama de las murallas tardorromanas hispanas se mueve dentro de un margen temporal de más de un siglo, que comprende desde mediados del siglo III d. C. hasta finales del siglo IV. Este fenómeno es extensible a las construcciones de carácter militar de las fronteras del Imperio (Lander, 1984, 151). Desconocemos si las fortificaciones hispanas obedecen a un único momento constructivo o a varios y, en este último caso, el posible escalonamiento de los mismos a lo largo de más de un siglo.

Sin embargo, el terminus post quem no es por sí mismo una fecha segura para la cronología del conjunto. En este sentido debemos estar prevenidos contra la tendencia a usar de forma generalizada e indiscriminada este dato. Los restos epigráficos, por poner un ejemplo, pueden haber sido reutilizados en la obra defensiva en un momento muy posterior a su amortización inicial. No se puede olvidar que lápidas y otros elementos arquitectónicos romanos han sido encontradas formando parte de construcciones de datación claramente medieval.

A la hora de asignar cronología a un recinto bajoimperial se ha acudido frecuentemente a los paralelismos tipológicos de plantas, puertas, torres o aparejos. Como bien ha señalado Lander: "La datación tipológica depende de analogías datables, y éstas son difíciles de lograr en el periodo tardorromano" (Lander, 1984, 151). No hace falta que hagamos hincapié en las dificultades añadidas que presenta el caso hispano.

\section{Muralla urbana y defensa del territorio}

Por lo que respecta a la distribución geográfica, las ciudades amuralladas bajoimperiales se concentran al norte del Sistema Central, correspondiente a las provincias Tarraconensis, Gallaecia y los extremos septentrionales de la Lusitania y la Carthaginensis. Al sur de esta línea imaginaria quedarían los recintos de Emerita, Ebora, Norba e Italica, además de Pollentia, en las Islas Baleares. Dentro de este panorama general se observa un significativo agrupamiento en el Noroeste peninsular.

Balil explicaba esta concentración al norte del Duero en términos de estrategia defensiva, cuyo objetivo primordial sería la protección de la línea Ebro-Duero (Balil, 1960, 196). El principal problema con el que nos encontramos al hablar de la distribución geográfica y de la finalidad de las defensas ciudadanas bajoimperiales es si existe una razón única que justifique la construcción de todas ellas en un momento cronológico próximo. Con la precariedad de los datos cronológicos disponibles, esta hipótesis no puede mantenerse con certeza. Resulta muy peligroso extrapolar la problemática de una a otra región e incluso, dentro de una misma área, de uno a 
otro recinto. Sería necesario contemplar cada caso por separado antes de llegar a formulaciones de conjunto. Por ahora no resulta sostenible la existencia de una estrategia defensiva global y generalizada a toda la Península, propuesta en la que encontramos numerosas lagunas y cuestiones sin respuesta.

Se ha interpretado que las ciudades deben sus recintos defensivos a su posición dentro del entramado viario peninsular. Sin embargo, aunque su relación con la red de comunicaciones romana está fuera de toda duda, cabe argumentar que esta posición geográfica estratégica es la responsable en último término de la existencia misma de la ciudad en un determinado lugar y de su mayor o menor prosperidad, dentro de la cual el amurallamiento es un fenómeno urbano más. Por otra parte, la historiografía tradicional ha esgrimido la psicosis de pánico provocada por las primeras oleadas bárbaras de época de Galieno como la razón que impulsó el amurallamiento general de Galia e Hispania. Para el caso hispano parece fuera de toda duda que las invasiones franco-alamanas afectaron a la costa catalano-levantina, aunque la existencia de una segunda invasión que, según algunos autores, devastó el Valle del Duero, plantea hoy en día numerosos problemas (6).

Es posible que en la creación de cada recinto amurallado influyeran de forma determinante las características particulares de cada ciudad en momentos concretos: su nivel económico, la potencia y continuidad de su vida urbana, su posición respecto a una hipotética amenaza bárbara... Tendrían cabida también las razones de prestigio personal apuntadas por Rebuffat (Rebuffat, 1974; Rebuffat, 1986), que han tenido bastante eco en investigadores posteriores. En este sentido tenemos que entender la aparente pérdida de importancia de determinadas ciudades altoimperiales, que quizá no pudieron hacer frente a costosos programas constructivos de fortificación, mientras otras de segunda categoría se amurallaban (Balil, 1963, 265; Barral i Altet, 1982 , 129). En cualquier caso no parece que las murallas ciudadanas hayan tenido alguna vez una auténtica operatividad defensiva (Balil, 1960, 182-3).

Si bien estas observaciones son aplicables en general al caso hispano, las ciudades del extremo oriental de la Gallaecia -Lucus, Asturica, Castra Legionis VII y Gijón- plantean una problemática algo diferente. Tratándose de núcleos urbanos en modo alguno comparables a las grandes ciudades de la Bética o de la Tarraconense durante el Alto Imperio, todas ellos se dotan de potentes sistemas defensivos tardoimperiales de gran extensión, que parecen guardar evidentes relaciones estructurales entre sí. La presencia de unidades militares en al menos dos de ellos, conocida a través de la Notitia Dignitatum, apunta una posible respuesta a esta cuestión. Podríamos defender la existencia de un estilo o programa de fortificación de ámbito exclusivamente regional, sobre cuyas motivaciones se han apuntado respuestas tan dispares como la supervisión minera (Johnson, 1983, 130), la defensa marítima en retaguardia (Arce, 1982, 84) o la vigilancia del recorrido de la annona militaris hacia el limes germánico, por no hablar de las trasnochadas teo-

(6) El tema de las invasiones del siglo III d. J. C. en Hispania ha sido tratado, entre otros, por los trabajos B. Taracena :"Las invasiones germánicas en España durane la segunda mitad del siglo III", I Congreso Int. Pirenaistas, Zaragoza, 1950, p. 5-13; M. Tarradell: "Sobre las invasiones germánicas del siglo III en la Península Ibérica”, Estudios Clásicos III, 1955-6, p. 56-110; "Problemas cronológicos de las invasiones germánicas del siglo III (a. de J. C.)”, IV C. N. A., Burgos, 1955 (pub. Zaragoza, 1957), p. 231-9; "La crisis del siglo III d. C. e Hispania: algunos aspectos fundamentales", I Congreso Español Est. Clásicos, 1956 (pub. 1958), p. 263 y ss.; J. Sánchez Real: "La invasión germánica del 259 en Tarragona", Boletín Arq. Tarraconense LI, 1951,129 y ss.; A. Balil: "Las invasiones germánicas en Hispania durante la segunda mitad del siglo III d. de J. C.", Cuad. Est. Escuela Esp. 
rías de un limes contra cántabros y astures (7). Fevrier ya defendió hace algunos años que las murallas del Noroeste peninsular respondían a un fenómeno tardío de urbanismo generalizado (Fevrier, 1974, 83).

Las características constructivas y la posición geográfica - a lo largo de vías de comunicación entre la Gallaecia y la zona pirenaica- de los recintos de Iruña e Inestrillas podrían indicar la existencia de una relación con el grupo del Noroeste, aunque la carencia de registros arqueológicos asimilables lo convierten en una hipótesis indemostrable. Las supuestas fortalezas para protección de Emerita, finalidad apuntada por Balil (Balil, 1960, 196) para recintos como Norba o Caurium, plantea incógnitas irresolubles. También en este caso, la imposibilidad de considerar algunos de éstos como bajoimperiales, unido a la ausencia de comprobaciones estratigráficas, dificulta la aceptación actual de esta hipótesis.

Como puede observarse en el mapa de distrubución, en la mitad meridional de la Península se observa un gran vacío de fortificaciones. Nada podemos decir acerca de la Submeseta sur, en la que las excavaciones realizadas en los principales núcleos urbanos no han revelado hasta la fecha resto alguno de defensas tardías. Por lo que se refiere a la Bética, la ausencia de este tipo de estructuras en época bajoimperial puede obedecer más a una carencia real que a retrasos en la investigación arqueológica urbana, por otro lado bastante avanzada en esta región. A primera vista esta laguna en nuestra documentación podría responder sencillamente a la vigencia de recintos defensivos de periodos anteriores. Este pudiera ser el caso no sólo de la Bética y el sur de la Cartaginense, sino también de otros núcleos urbanos peninsulares de la envergadura de Tarraco o Carthago Nova.

No hay que descartar bajo ningún concepto que futuras comprobaciones arqueológicas en recintos hasta ahora poco explorados varíen sustancialmente este panorama.

\section{CONCLUSIONES}

Después de este largo estado de la cuestión, creemos llegado el momento de observar bajo una nueva óptica el problema de la fortificación urbana bajoimperial en Hispania. Ya Balil, en 1960, apuntaba "el escaso interés que ha existido hasta hace algunos decenios en el estudio de las fortificaciones romanas de Hispania, razón por la cual la cronología de algunas fortificaciones es muy insegura" (Balil, 1960, 185). Afortunadamente, las investigaciones realizadas durante los últimos veinte años han variado de forma paulatina este panorama descrito por Balil. La labor continuada de los arqueólogos ha añadido nuevos recintos como Tiermes y Gijón a la nómina de las murallas bajoimperiales, mientras ha sometido algunos otros a una crítica seria y metodológica. Sin embargo, las carencias siguen siendo significativas en este campo.

... Arq. Roma IX, 1957, 95 y ss.; ibid. "Hispania, en los años 260-300 d. d. J. C.", Emerita XXVII, 1959, p. 269-95; J. Ramos Fernández: "Las invasiones de los francos en España”, Anales Univ. Murcia XXIII, 3-4, 1964-5, 254-81; J. M. Blázquez: "La crisis del siglo III en Hispania y Mauritania Tingitana", Hispania XXVIII, 1968, p. 5-37; J. Arce: "La crisis del siglo III en Hispania y las invasiones bárbaras", Hispania Antiqua VIII, 1978, p. 257-78; L. Sagredo San Eustaquio: Circulación e inflación monetaria en la Hispania romana del siglo III d. C., Valladolid, 1983; ibid "Sobre la supuesta invasión del siglo III d. C. en la Meseta norte", I Congreso Historia Palencia, I, Palencia, 1985 (pub. 1987), p. 531-57; A. González Prats y J. M. Abascal: "La ocultación monetaria de la D'Eula, Crevillente (Alicante) y su significación para el estudio de las invasiones del siglo III", Lucentum 6, 1987, p. 183-90.

(7) Cfr. nota no 5 . 
A la luz de los nuevos descubrimientos, habría que comenzar a desterrar determinados tópicos que se han venido repitiendo sistematicamente desde los primeros estudios dedicados a este tema. Apuntar algunos nuevos enfoques pretende ser nuestra modesta contribución al tema, que dista mucho de estar cerrado.

De un primer análisis de este conjunto de fortificaciones se desprende que no son muchos los recintos que pueden considerarse bajoimperiales con suficientes garantías. De los 43 recintos amurallados a los que se ha atribuido en algún momento una cronología tardorromana, estimamos que tan sólo 17 de ellos reunen las condiciones mínimas para ser asignados a este periodo.

A la vista de lo conocido hasta la fecha, en la Península Ibérica no se produjo una reducción generalizada del perímetro urbano bajoimperial. El único caso comprobado arqueologicamente es Conimbriga y, posiblemente en un futuro, podamos decir lo mismo de Italica. El resto de las ciudades amuralladas no parece haber variado significativamente su perímetro, a excepción del grupo de la Gallaecia, donde se levantaron ex-novo recintos que engloban superficies muy superiores a lo que sería previsible para núcleos urbanos de tipo medio y de romanización más reciente.

Una gran variedad tipológica y estructural preside la edificación de los recintos bajoimperiales en Hispania. Bajo esta óptica no resultan defendibles los criterios de clasificación estilística, tal y como creemos que ha quedado suficientemente demostrado en nuestro estudio preliminar. Siguen siendo válidas, sin embargo, las observaciones de Richmond y Balil sobre la multiplicación de torres, rasgo especialmente acusado en las murallas hispánicas.

La aparición de restos epigráficos empotrados en los paramentos o en el relleno de las murallas sólo puede tomarse como un dato relativo, sin lugar a dudas orientativo, pero sobre el que no se puede fundamentar el origen tardorromano de una fortificación. Sin el concurso de datos arqueológicos fehacientes no es posible elaborar atribuciones cronológicas incontestables. Por otra parte, el empleo de restos constructivos reutilizados en la fábrica de una muralla no implica necesariamente su rapidez constructiva -tal y como ya apuntó Balil en su momento (Balil, 1958, 282)- sino tan sólo el uso de los recursos más cercanos y la búsqueda de un abaratamiento de los costes, en una obra de envergadura considerable. En definitiva, el ahorro siempre sería relativo. Balil también señaló, entre las posibles causas de la reutilización de materiales anteriores, la necesidad de eliminar los obstáculos que impedían el trazado de la muralla o la creación de una franja de seguridad delante de la misma (Balil, 1960, 181-2). No nos parece adecuado seguir empleando el socorrido argumento de las reutilizaciones como base de armazones de corte histórico. La amenaza de los bárbaros no puede ser la tabla de salvación a la que acogerse cuando no se dispone de otro tipo de registro cronológico.

El terminus post quem, con todas sus objeciones, parece ser el único recurso del que disponemos para llegar a ciertas conclusiones sobre la cronología de una muralla tardía. No debemos subestimarlo como criterio de orientación global, pero resulta ineficaz a la hora de delimitar periodos más cortos. Esta es, sin duda, la causa principal de que en el tema de las fortificaciones bajoimperiales hispanas nos movamos dentro de la etiqueta insatisfactoria de "fines del siglo III e inicios del siglo IV". En realidad, podríamos prolongar este supuesto momento constructivo hasta los primeros años del siglo V. Aquilatar dentro de este siglo y medio de tardorromanidad hispana con los datos disponibles es, a todas luces, imposible, si exceptuamos tal vez algún caso aislado como Gerunda.

Ante la irregular distribución geográfica de recintos bajoimperiales en Hispania, debemos plantearnos si la provincia estuvo en verdad imbricada en algún programa o programas de fortificación de los que se pusieron en práctica en las provincias occidentales entre Diocleciano y Honorio. Las razones de tipo geográfico-estratégico -la famosa "defensa en profundidad"- no 
resultan por sí solas suficientes para defender esta hipótesis, que tantos seguidores ha tenido. Por otra parte, esta interpretación de Balil partía del supuesto de una evolución en el estilo de las fortificaciones hispanas, que hoy en día no se puede probar (Balil, 1960, 196-7). Si bien no podemos negar la posiblidad de una motivación común para el amurallamiento hispano, la variedad tipológica y la inexactitud cronológica de los recintos complica extraordinariamente cualquier tentativa de establecer grupos de ciudades con características constructivas semejantes, que pudieran avalar un único momento histórico para todas ellas. Solamente la comprobación estratigráfica de depósitos cerrados en murallas ya conocidas y la posible constación de otras nuevas, podría aportar alguna luz al respecto.

Tal vez más que un programa o estrategia de fortificación generalizada, deberiamos considerar la posibilidad de que la erección de una muralla estuviera en función de la casuística concreta de cada núcleo urbano, en la que infuirían, entre otras, razones económicas, estratégicas, defensivas o de prestigio. Dentro de este fenómeno urbanístico consideramos un capítulo aparte, en el que no vamos a entrar, el de la reparación de obras defensivas anteriores, aún plenamente operativas a mediados del siglo III.

Tan sólo entre las ciudades del Noroeste peninsular -Lucus, Asturica, Castra Legionis VII Geminae y Gijón- existen analogías suficientes como para pensar en la aplicación específica de un programa regional de fortificación. La presencia del ejército en esta zona, determinada por razones aún no aclaradas convenientemente, proporciona una base argumental de cierta solidez para explicar este peculiar comportamiento de la Gallaecia. El momento de esta hipotética intervención urbanística en las ciudades del Noroeste está por precisar. Ningún dato objetivo nos lleva a pensar que, tal como opinaba Balil, este momento fuera anterior al de otros recintos hispanos (Balil, 1960, 196-7). Tampoco está suficientemente contrastada la intervención directa de unidades militares en la edificación de las murallas. 


\section{ADDENDUM}

Ya en prensa este artículo, hemos recibido nuevos datos sobre recintos ya descritos en la primera parte del mismo, publicada en el número anterior de esta revista, información que, por motivos obvios, no ha podido ser incluída en el estudio global que aquí presentamos.

Gracias a C. García Merino hemos tenido conocimiento de los nuevos hallazgos realizados en la ciudad de Uxama, concretamente en la Casa de la Atalaya. En este sector se documentó una muralla tardía de unos 3 metros de anchura, realizada en sillarejo, que reutiliza parte de un muro perteneciente auna habitación de la vivienda romana, dotada en época altoimperial. C. García Merino considera que la estructura defensiva debe edificarse a finales del siglo IV o comienzos del V d.c. (García Merino, C. Guía de Uxama (e.p.). Agradecemos a esta investigadora los datos inéditos aquí presentados, que permiten incluir la muralla de Uxama entre los bajoimperiales.

Por lo que se refiere a la muralla de Ilici, también incluída en la primera parte de este estudio (Fernández Ochoa, C. y Morillo, A. 1991: "Fortificaciones urbanas de época bajoimperial en Hispania. Una aproximación crítica. Cupauam 18, 248-9), debemos reseñar una nueva mención a su carácter tardío, recogida por varios autores (Ramos Fernández, R. y Uroz Saez, J. 1992: "Ilici", Dialoghi di Archeologia 10, 1-2 (Conquista romana y modos de intervención en la organización urbana y territorial), 103, nota 40; Abad, L. y Aranegui, C. 1993: "Las ciudades romanas de los ámbitos levantino y baleárico", La Ciudad Hispanorromana, Tarragona, 98). En estos trabajos se describe la técnica edilicia de la fortificación de Ilici, de unos 6 metros de grosor y 4 metros de altura, realizada con núcleo de hormigón y paramento exterior de sillares irregulares. Estaba reforzada con torres cuadradas y se conservan restos de una de las puertas. De nuevo en este caso estamos a la espera de una publicación más completa.

Entre las fortificaciones de dudosa adscripción bajoimperial, debemos reseñar dos nuevas, los de la antigua Pompaelo y las de Santander. En las excavaciones realizadas por M.A. Mezquíriz bajo el claustro de la Catedral de Pamplona apareció un lienzo realizado mediante doble paramento de piedra y relleno interior se localizaron asimismo restos de una puerta. M.A. Mezquíriz data la estructura a fines del III o comienzos del siglo IV d.c. por el hallazgo junto a sus cimientos de cerámica tardo-romana. Sin embargo, la anchura de esta obra, unos 1,25 metros y la carencia de una documentación arqueológica más exhaustiva proyectan por el momento serias dudas sobre la atribución cronológica al periodo bajoimperial (V. Mezquíriz, M. A. 1983: "Localización de un lienzo de la muralla romana de Pompaelo" Homenaje al Profesor Martín Almagro Basch, III, Madrid, 275-8).

Durante las excavaciones arqueólogicas realizadas en 1982-83 en la cripta de la Catedral de Santander, aparecieron los cimientos de un muro de unos 3 metros de espesor, interpretado por J. González Echegaray y J.L. Casado Soto como el costado occidental de una muralla bajoimperial, cuya existencia debemos considerar más que dudosa por el momento. Sobre este hallazgo sólo se han publicado breves noticias (González Echegaray, J. y Casado Soto, J.L. 1983: "Excavaciones bajo la Catedral de Santander" Cantabria Autónoma, año II, no 3, 38-9; Casado Soto, J.L. y González Echegaray, J. 1985: "Cristo. Excavaciones bajo la parroquia del Santísimo. Arqueología”, Gran Enciclopedia de Cantabria, Santander, III, 90-91). 


\section{BIBLIOGRAFIA}

DE ABEL VILELA, A. 1975 a : Doscientos años de obras y restauraciones en la muralla de Lugo, Lugo.

... 1975 b: Guia de Las Murallas Romanas de Lugo, Madrid.

AlarCÃo, J. de 1973: Portugal romano, Lisboa.

... 1988: Portugal romano, Warminster.

AlarCĀo, J. de y ETIENNE, R. 1977: Fouilles de Conimbriga. I:L'Arquitecture, Paris.

Almagro BasCH, M. 1976: "La topografía de Augusta Emerita", Symposium Ciudades Augusteas, Zarago$\mathrm{za}, 189-211$.

Almeida, F. de 1956 a: Egitania. Historia e Arqueologia, Lisboa.

... 1956 b: "Notas sobre as primeiras escavaçoes em Idanha-a-Velha", XXIII Congresso Luso-Espanhol para o Progresso das Ciências, Lisboa, 9-14.

... 1965: "Um "palatium episcopi“ do sec. VI em Idanha-a-Velha (Portugal)" IX C. N. A., 408-11.

... 1977: Ruinas de Idanha-a-Velha, Civitas Igaeditanorum. Egitânia, Lisboa.

Alonso SANCHEZ, A. 1983: "El sistema de puertas en las murallas romanas de Hispania", Vettonia 1, 4959.

... 1988: Fortificaciones romanas en Extremadura. La defensa del territorio, Cáceres.

Alonso Sanchez, M. A. y Fernandez OChOA, C. 1988: "Cerámica Africana D con decoración paleocristiana en la muralla de Gijón”, Cu.P.A.U.A.M. 15, 339-77.

Alvarez Martinez, J. M. 1985: “Excavaciones en Augusta Emerita”, Arqueologia Ciudades Modernas Superpuestas a las Antiguas (Zaragoza, 1983), Zaragoza, 35-53.

... 1991: La ciudad romana de Mérida, Cuadernos Arte Español (ed. Historia 16) 6, Madrid.

... 1976: "La fundación de Mérida", Actas Bimilenario Mérida, Madrid, 19-30.

ARCE, J. 1982: El último siglo de la España romana: 284-409, Madrid.

... 1982 b: "Mérida tardorromana (284-409 d. C)", Homenaje a Saenz Buruaga, Madrid, 284-309.

ARIAS VILAS, F. 1972: La muralla de Lugo, Studia Arqueológica 14, Santiago de C.

AYVES, C. 1896: Historia organica e politica do exercito portugues I, Lisboa.

BaLIL, A. 1957: "La cronología de las fortificaciones de Barcino en el Alto Imperio", IV C. N. A (Burgos, 1955), Zaragoza, 227-30.

.. 1958: "Los trabajos de fortificación en las provincias del Occidente romano después de la crisis del siglo III y su significación política, militar y social”, Actas I Congreso Español Est. Clásicos (Madrid, 1956), Madrid, 281-4.

... 1960: "La defensa de Hispania en el Bajo Imperio", Zephyrus XI, 179-97.

... 1961: Las murallas romanas de Barcelona, Anejos A. Esp. A. II, Madrid.

... 1963: "Las fortificaciones del Bajo Imperio en las provincias romanas de España", Celticum XI, 293-6.

... 1965: "Urbanismo romano en la España céltica", Celticum XII, 275-88.

.. 1970: "La defensa de Hispania en el Bajo Imperio. Amenaza exterior e inquietud interna", Legio VII Gemina, León, 601-20.

Bairrao Oleiro, J. M. 1955-6: "O Criptoportico de Aeminium", Humanitas nova serie IV-V, 151-60.

BARRAL I ALTET, X. 1982: "Transformacions de la topografía urbana a la Hispània cristiana durant l'antiguitat tardana”, II Reunió d'Arqueologia Paleocristiana Hispànica, Montserrat, 105-32.

Barreto Nunes, H. 1978: “O Salvamento de Bracara Augusta III", Actas III Jornadas Arqueológicas I, (Lisboa, 1977) Lisboa, 225-36.

Bedon, R., CheValier, R. y Pinon, P. 1988: Architecture et urbanisme en Gaule romaine, Paris

Bellino, A. 1909: “Cidades mortas”, O Arch. Portugues XIV, 1-28. 
Beltran Lloris, M. 1975-6: “Aportaciones a la epigrafía y arqueología romana de Cáceres”, Caesaraugusta 39-40, 19-112.

... 1982: Museo de Cáceres. Sección de Arqueología, Madrid.

BlaZQueZ, J. M. 1965: Caparra, Exc. Arq. Esp. 34, Madrid.

Boletim dos Monumentos Nacionais (1948): Oppidum romano de Conimbriga, Boletim da Direçccao Geral dos Edificios e Monumentos Nacionais LII-LIII.

CALERO, J. A. 1992: "La muralla romana de Augusta Emerita: Apuntes para una bibliografía crítica de los estudios sobre el recinto", Rev. Estudios Extremeños XLIX, I, 259-275.

Callejero Serrano, C. 1964: Sobre el origen del nombre de Cáceres, Cáceres.

... 1968: "La arqueología de Norba Cesarina", A. Esp. A. 41, 121-49.

CARreño, C. 1991. "Crónica das excavacións de urxencia feitas na Cidade de Lugo durante o ano 1989 polos servicios municipais de Arqueoloxía”, Larouco, I, 99-106.

Do Carmo SAmpaio, R. 1962: "Bracara Augusta. Nota para a sua história e arqueología", Actas II Coloquio Portuense de Arqueologia en Lucerna III, Porto, 260-7.

CEAN BERMUdEZ, J. A. 1832: Sumario de las antigüedades romanas que hay en España, Madrid.

Contador de ARgote, J. 1728: De Antiquitatibus Conventus Bracaraugustani, Colleç̧ons dos Documentos e Memorias d. Academia Real de Historia Portuguesa.

... 1747: Memorias de Arcebispado de Braga.

Correia, V. 1940-1: "Las más recientes excavaciones romanas de interés en Portugal. La ciudad de Conimbriga”, A. Esp. A. XIV, 257-67.

... 1952: Inventario artistico de Portugal. IV. Distrito de Coimbra, Lisboa.

CORREIA, J. M. 1945: "Idanha-a-Velha", Museu 4, 106-7.

Delgado, M. y VV. AA. 1984: "Intervençoes na área urbana de Bracara Augusta (1983)", Cuadernos de Arqueologia, serie II, vol. I, 95-106.

Diaz y PereZ, N. 1887: España. Sus monumentos y sus artes. Su Naturaleza e Historia. Extremadura, Barcelona.

Diez Martos, A. 1956: "Las murallas de Coria", Rev. Est. Extremeños 12, 263-95.

Dotor, A. 1965: "Coria, una ciudad romana y medieval", Bol. Asociación Esp. Amigos Castillos 49, 141-51.

ESPANCA, T. 1949: Evora. Guía histórico-artistica, Evora.

... 1966: Inventário artístico de Portugal VII. Concelho de Evora I, Lisboa.

FERNANDEZ OCHOA, C. 1983: "Excavaciones arqueológicas en el área urbana de Gijón: descubrimiento de la muralla romana", I Jornadas Arqueologia en Ciudades Actuales, Zaragoza, 143-52.

FERNANDEZ OCHOA, C. y VV. AA. 1984: "Excavaciones en la muralla romana de Cimadevilla", Gijón Romano, Gijón, 63-80.

FERnANDEZ OCHOA, C. 1986: "Ultimos resultados de las excavaciones de la muralla de Cimadevilla", $I$ Congreso Int. Astorga Romana, Astorga, 329-41.

Fernandez OChOA, C. y Martinez Diaz B., 1986-7: "Gijón, fortaleza romana en el Cantábrico", $C u$. P.A.U.A.M. 13-14, 185-203.

FERNANDEZ OCHOA, C. 1992 a: "Excavaciones en la muralla romana de Cimadevilla (Gijón)", Exc. Arq. Asturias 1987-90, Oviedo, 152-9.

... 1992 b: "La muralla romana de Cimadevilla (Gijón)", Los orígenes de Gijón, Gijón.

FEVRIER, P. A. 1974; "Permanences et héritages de l'Antiquité dans la topographie des villes de l'Occident durant le Haut Moyen Age", Topografia urbana e vita cittadina sull'alto medioevo in Occidente. Settimane di Studio del Centro Italiano di Studi sull' alto medioevo XXI, Spoleto (1973), 41-284.

Floriano Cumbreño, A. 1944: "Excavaciones en la antigua Cappara (Cáparra, Cáceres)”, A. Esp. A. 17, 270-86. 
... 1957: Estudios de Historia de Cáceres. Desde los orígenes a la Reconquista, Oviedo.

Fuentes DOMINGueZ, A. 1988: La necrópolis tardorromana de Albalate de las Nogueras (Cuenca) y el problema de las denominadas "Necrópolis del Duero", Cuenca.

GarCIA Y BELlido, A. 1948: "Ultimas novedades portuguesas", A. Esp. A. XXI, 281-4.

... 1962: "Excavaciones en Augustobriga (Talavera la Vieja, Cáceres), Not. Arq. Hisp. V, 1956-61, 235-7.

... 1968 a: Nueve estudios sobre la Legio VII Gemina y su campamento en León, León (repetido en ""Estudios sobre la Legio VII Gemina y su campamento en León”, Legio VII Gemina, León, 1970, 571-99).

... 1968 b: "León y la Legio VII Gemina con motivo del XIX centenario de su creación", XIX Centenario Creación Legio VII Gemina. Programa General León, s/p.

... 1971: "El recinto mural romano de Evora", Conimbriga X, 85-92.

Garcia Moreno, L. 1986: "Las transformaciones de la topografía de las ciudades en Lusitania en la Antigüedad Tardía", Rev. Estudios Extremeños 42, 97-114.

Gaspar, A., Sande Lemos, F. y Delgado, M. 1986: “O Salvamento de Bracara Augusta. Reflexoes”, I Encontro Nacional Arq. Urbana, (Setubal, 1985), Trabalhos de Arqueologia 3, Lisboa, 27-42.

Gomez-Moreno, M. 1925: Catálogo Monumental de España. Provincia de León, Madrid.

Granados, J. O. 1977-8: “Excavación de la torre de flanqueo sudoeste de la puerta Decumana de la Colonia Barcino", Pyrenae 13-14, 253-73.

Jimenez Martin, A. 1976: "Los Acueductos de Emerita”, Binilenario Emerita Augusta, Mérida, III-25. Johnson, S. 1983: Late Roman Fortifications, London.

LANDER, J. 1984: Roman Stone Fortifications. Variation and Change from the First Century A. D. to the Fourth, B. A. R. 206, Oxford.

LaRa Peinado, F. 1973: Lérida romana, Lérida.

Luengo, J. M. 1962: “Astorga romana. Excavaciones del Plan Nacional 1954-5”, Not. Arq. Hisp. V, 1956-61, 152-77.

MALUQUeR De MOTES, J. 1968: “Excavaciones en el Castro de Las Merchanas”, Pyrenae 4, 101-28.

Mañanes, T. 1976: “Asturica Augusta”, Symp. Ciudades Augusteas, Zaragoza, 77-84.

... 1982: Epigrafia y numismática de Astorga romana y su entorno, Salamanca.

... 1983: Astorga romana y su entorno. Estudio Arqueológico, Valladolid.

... 1984: "Asturica Augusta. La ciudad y su entorno", Portugalia IV-V (Actas do Coloquio Interuniversitario de Arqueología do Noroeste), 215-29.

... 1985: "Excavaciones en las murallas de Astorga (1971-2)", Not. Arq. Hisp. 21, 183-219.

MARTINEZ, R. 1901: "Coria", Revista de Extremadura III, 26-7

Martinez Lillo, S. 1990: "Arquitectura militar de ámbito rural de la Marca Media (Al-Tagr al-awsat). Antecedentes y Evolución”, Bol. Arq. Medieval 4, 135-71.

Mateo Marcos, J. 1979: "León. Origen, evolución y decadencia de un recinto amurallado", Symp. Nacional Castillos (repetido en Origen, evolución y decadencia del recinto amurallado de León, León, 1981.

Matilla Vicente, E. 1983: “Legio VII Gemina y León”, Lancia 1, 263-71.

MelidA, J. R. 1921: "Informe sobre las murallas de Lugo", Bol. Real academia Bellas Artes, Madrid.

... 1924: Catálogo Monumental de España. Provincia de Cáceres II, Madrid.

... 1925: Monumentos romanos de España, Madrid.

Morillo Cerdan, A. 1991: "Fortificaciones campamentales de época romana en España", A. Esp. A. 64, $135-90$.

Moutihno Alarcāo, A., Mayet, F. y Nolen, J. S. 1989: Ruinas de Conimbriga, Routeiros da Arqueologia Portuguesa 2 ( $2^{\circ} \mathrm{ed}$.), Lisboa. 
Olmo EnCISO, L. 1985: "Problemática de las fortificaciones altomedievales (siglos VI-VIII) a raiz de los últimos hallazgos arqueológicos”, I Congreso Arq. Medieval Española, Huesca, 13-23.

Pallares, F. 1969: "Las excavaciones de la Plaza de San Miguel y la topografía romana de Barcino", Cuad. Arq. Historia Ciudad XIII, 5-42.

Palol, P. de 1952: "Castro hispanovisigodo de Puig Rom (Rosas)", Informes y Memorias 27, 163-82.

Pereira, G. 1885: Estudos Eborenses I. Evora romana I, Evora.

... 1900: "Antigüedades romanas de Evora", O Arq. Portugues 5, 110-35.

Pereira, F. A. 1938: "Vestigios do passado em Idanha-a-Velha”, O Arq. Portugues 30, 186-204.

Pita Merce, R. 1967: “La muralla romana de Ager”, A. Esp. A. XL, 104-9.

Rebuffat, R. 1974: "Enceintes urbaines et insegurité en Maurétanie Tingitane", M. E. F. R. A. 86, Roma, 501-22.

... 1986: "Les fortifications urbaines romaines", La Fortification dans l'histoire du monde grec, Paris, 34561.

RICHMOND, I. A. 1931: "Five town-walls in Hispania Citerior", J. R. S. XXI, 86-100.

Rigaud de SousA, J. J. 1973: Subsidios para a Carta arqueologica de Braga, Studia Archaeologica 23, Santiago de Compostela.

SOMOZA, J. (1908): Gijón en la Historia general de Asturias, Gijón.

TARACENA, B. 1924-5: "Excavaciones en algunos sitios de la provincia de Soria", M. J. S. E. A. 70, 1-31.

... 1949: "Las fortificaciones y la población de la España romana”, Cong. Arq. Sureste Español (Elche, 1948), Zaragoza, 421-41.

Teixeira, J. 1910: Apontamentos Arqueológicos de Cidade de Braga, Manuscrito da Biblioteca Publica de Braga MM 310.

ThOuVENOT, R. 1961: “Les remparts romains de Coria d'Estramadoure", R. E. A. 63, 331-40.

TranoY, A. 1981: La Galice romaine, Paris.

SALAS MARTIN, J. 1982: Cáceres romano: contexto histórico y arqueología, Cáceres.

SCHUlten, A. 1943: Los Cántabros y Astures y su guerra con Roma, Madrid.

VAZQUEZ SeIJAS, M. 1955: Fortalezas de Lugo y su provincia I, Lugo.

Velo Nieto, G. 1947: Coria, bosquejo histórico de esta ciudad y su comarca, Madrid.

Wattemberg. F. 1961-2: "El castellum romano de San Pedro de Latarce (Valladolid)", Homenaje al Prof. Cayetano de Mergelina, Murcia, 845-60. 


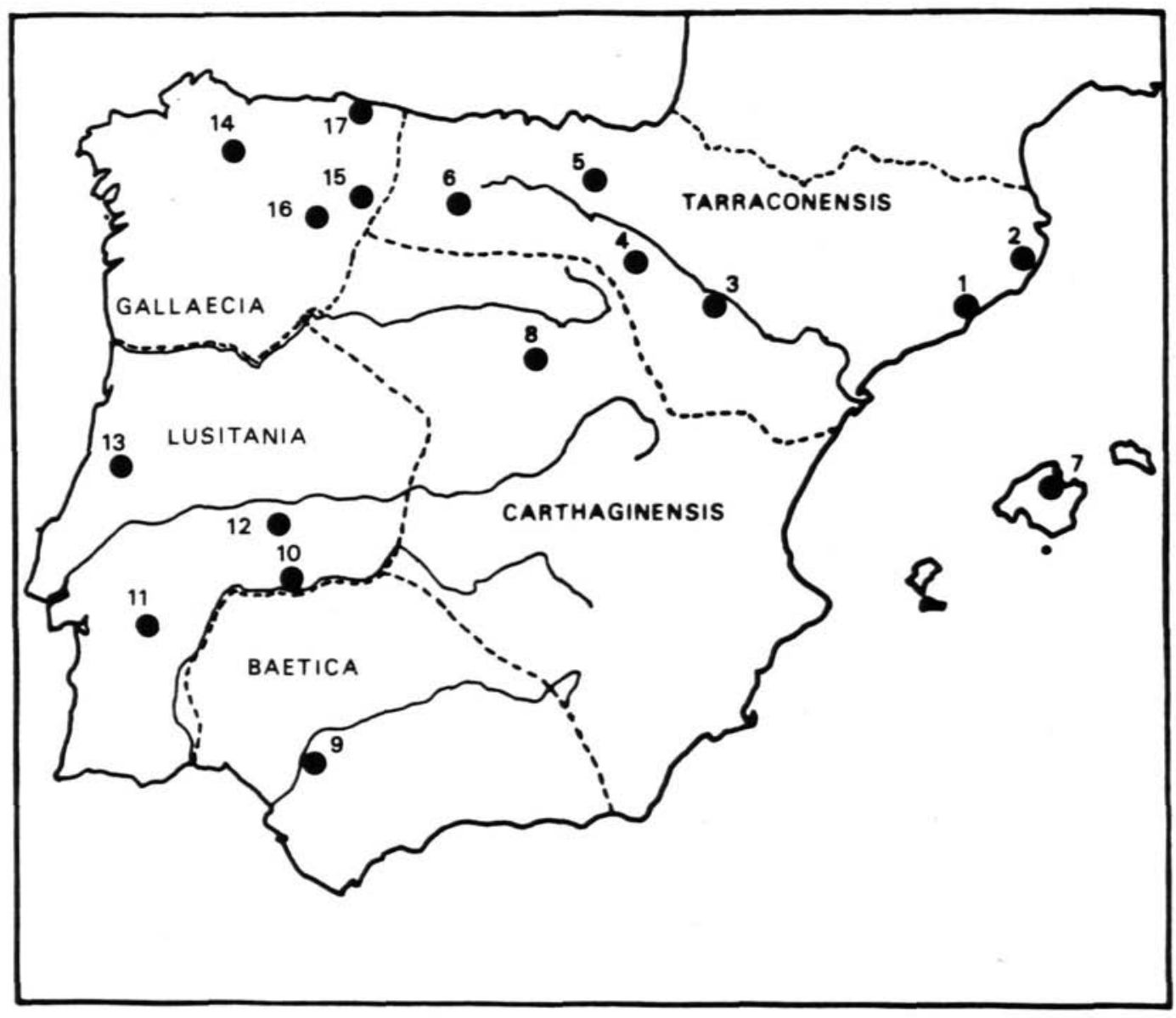
1. BARCINO
2. GERUNDA
3. CAESARAUGUSTA
4. INESTRILLAS
5. IRUÑ A
6. MONTE CILDA
7. POLLENTIA
8. TIERMES
9. ITALICA

10. EMERITA AUGUSTA

11. EBORA

12. NORBA CAESARINA

13. CONIMBRIGA

14. LOCUS AUGUSTI

15.CASTRA LEGIONS VII GEMINAE

16. AUSTURICA AUGUSTA

17. GIJON

Figura 1. Recintos amurallados urbanos de época bajoimperial en Hispania 


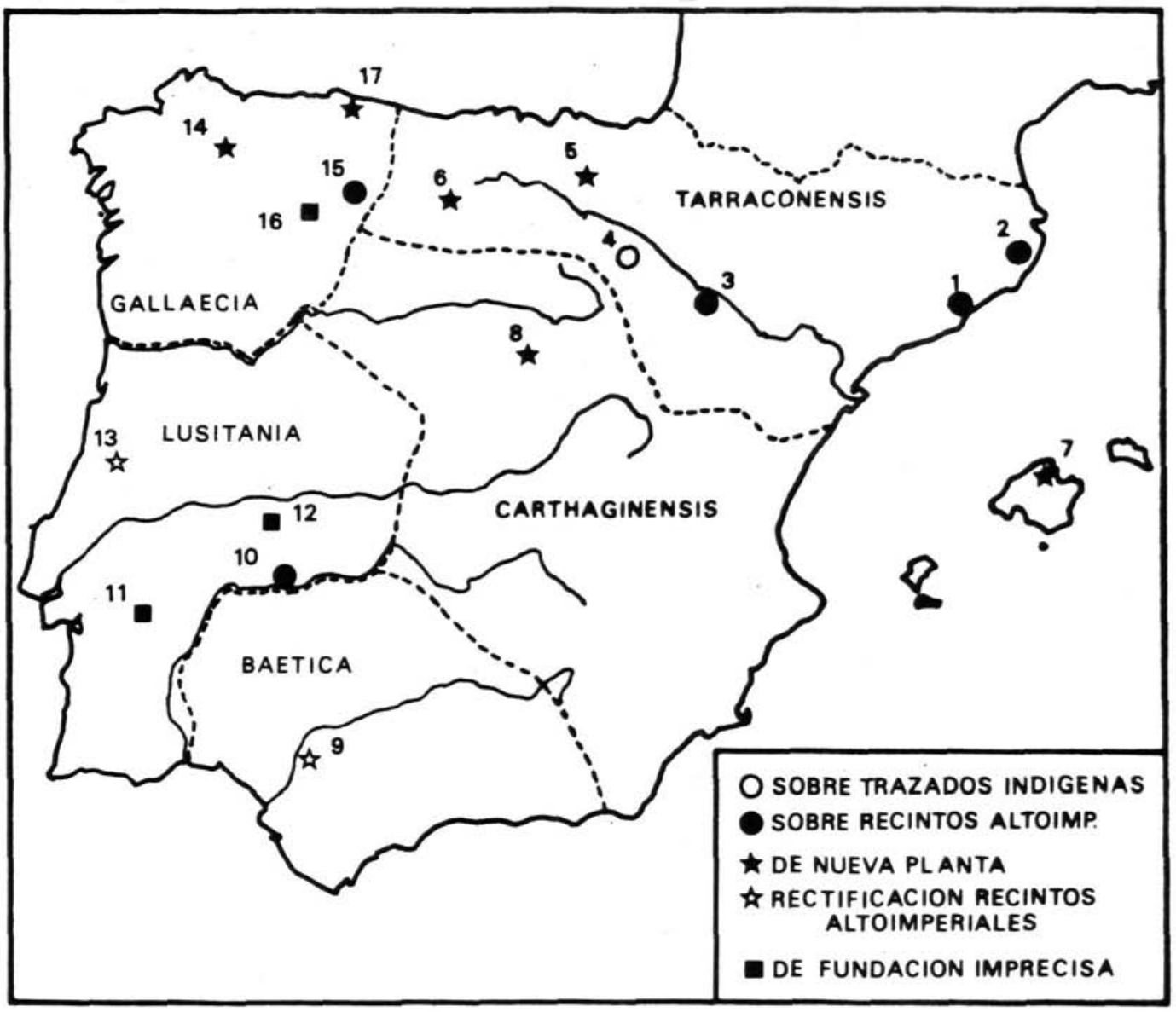
1. BARCINO
10. EMERITA AUGUSTA
2. GERUNDA
11. EBORA
3. CAESARAUGUSTA
12. NORBA CAESARINA
4. INESTRILLAS
13. CONIMBRIGA
5. IRUNAA
14. LOCUS AUGUSTI
6. MONTE CILDA
15.CASTRA LEGIONS VII GEMINAE
7. POLLENTIA
16. AUSTURICA AUGUSTA
8. TIERMES
17. GIJON
9. ITALICA

Figura 2. Clasificación de murallas bajoimperiales según su origen 


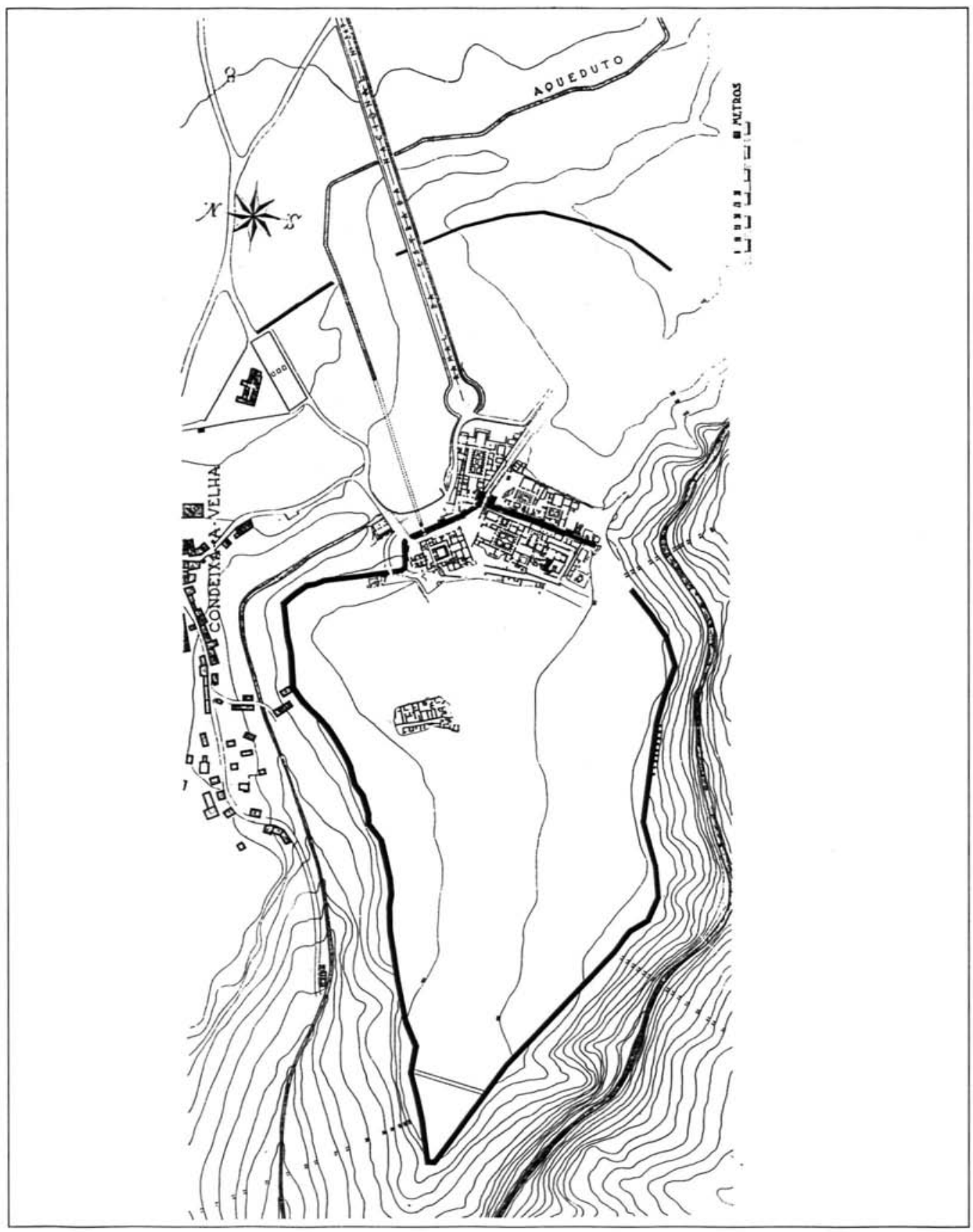

Figura 3. Planta del recinto amurallado de Conimbriga (Boletín Dos Monumentos Nacionais, 1948) 


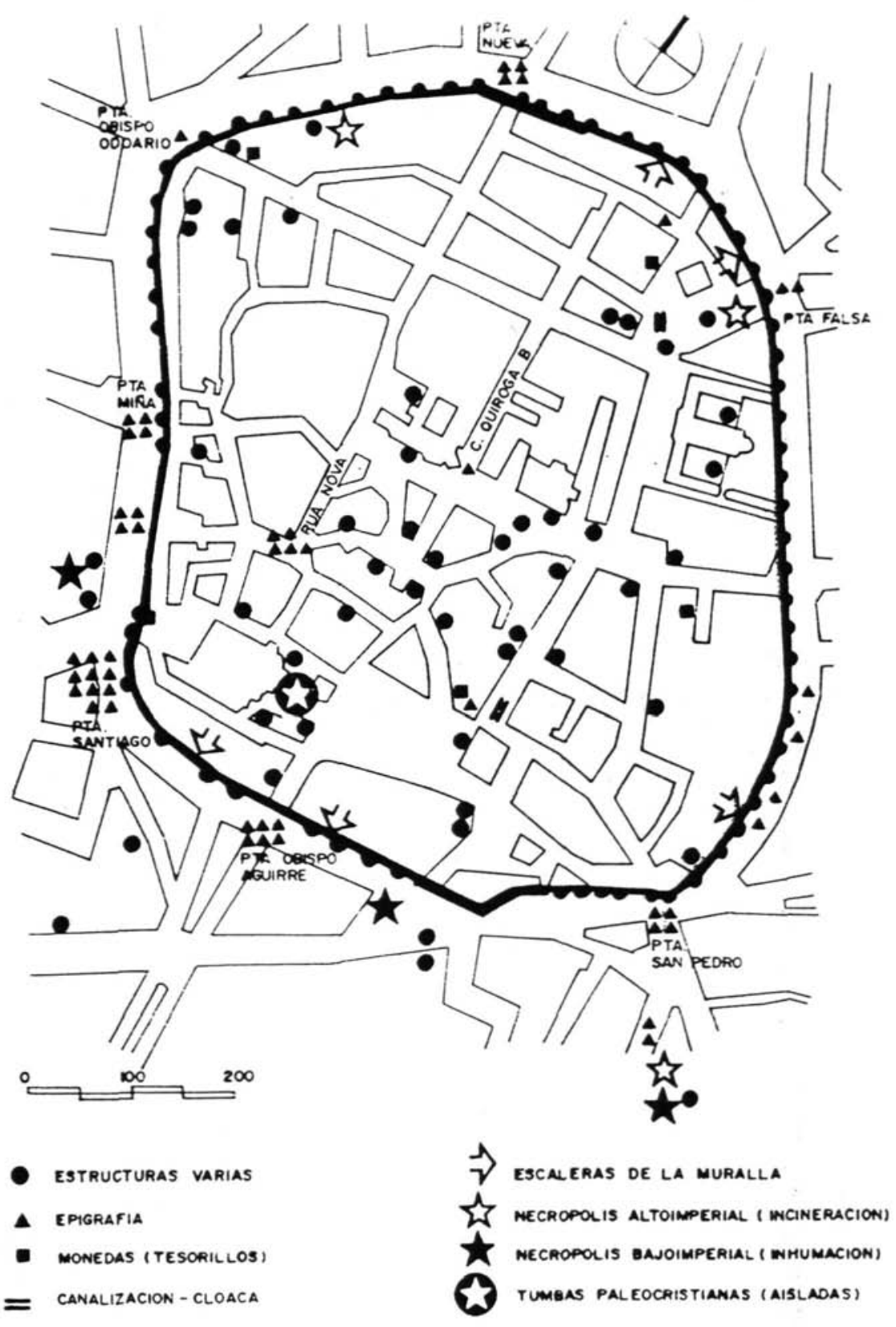

Figura 4. Planta del recinto amurallado de Lucus Augusti con distribución de hallazgos (Arias Vilas, 1990) 


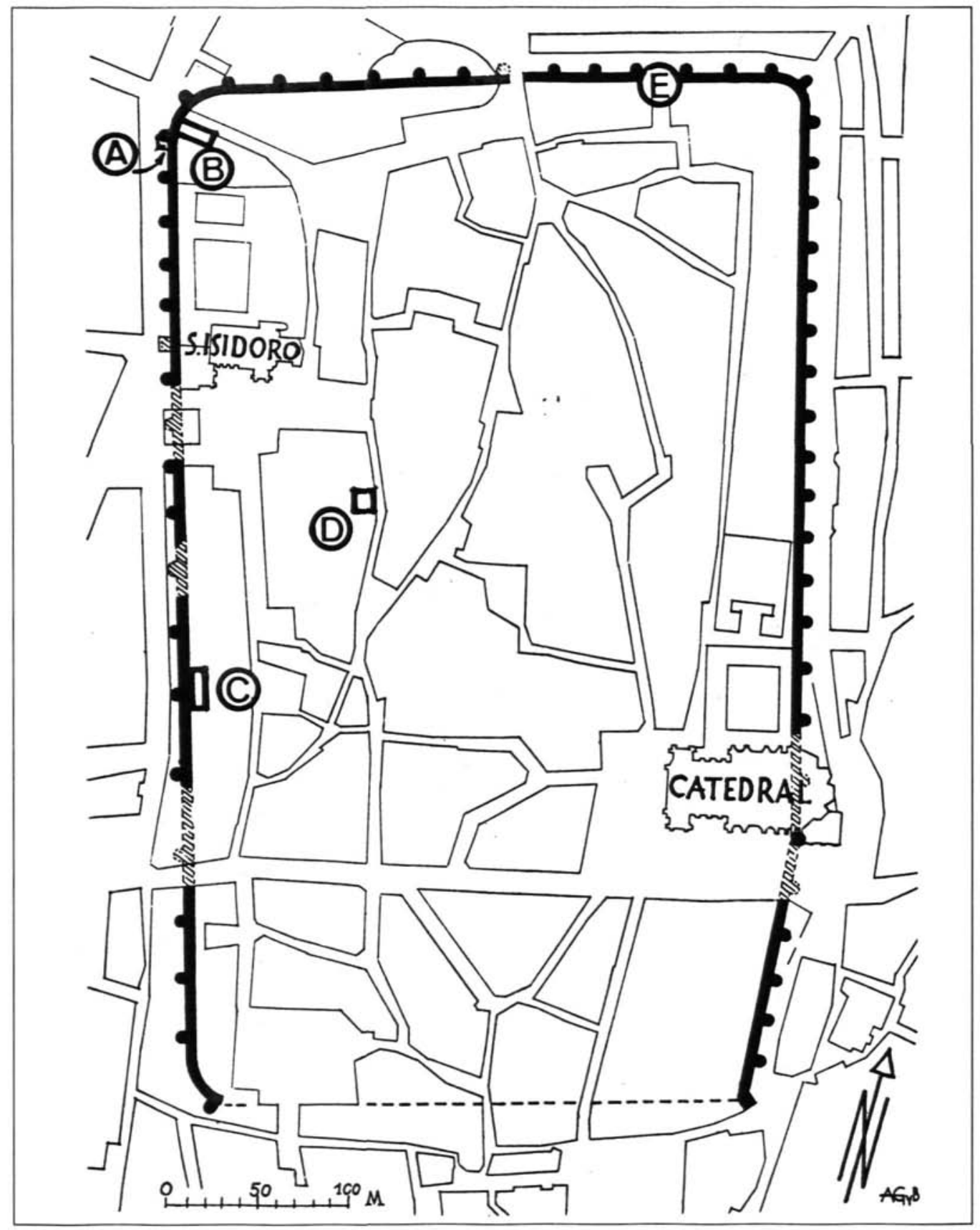

Figura 5. Planta del recinto amurallado de Leon (García y Bellido, 1970) 


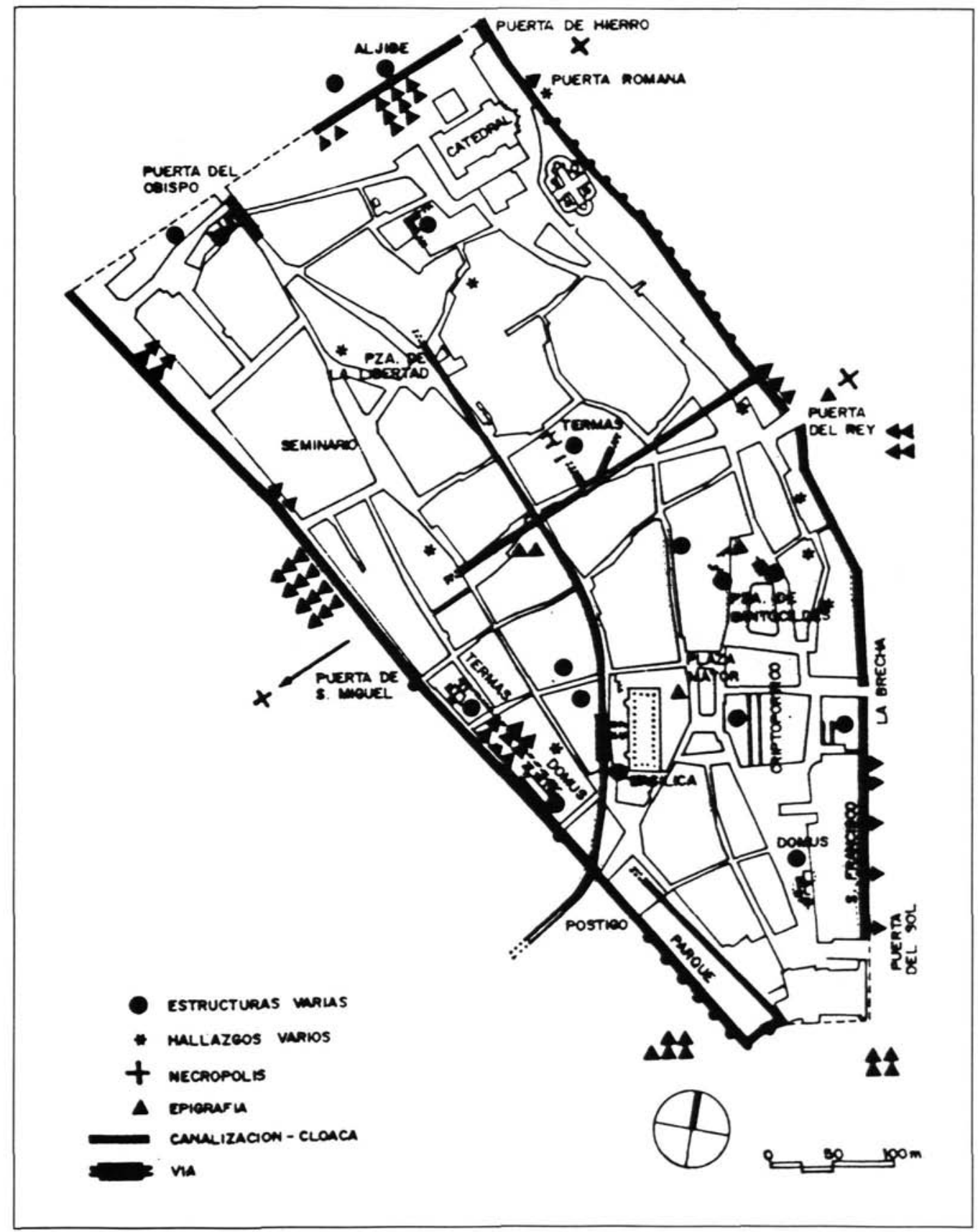

Figura 6. Planta de Asturica Augusta con distribución de hallazgos (Servicio Territorial de León, Junta de Castilla y León, 1990) 


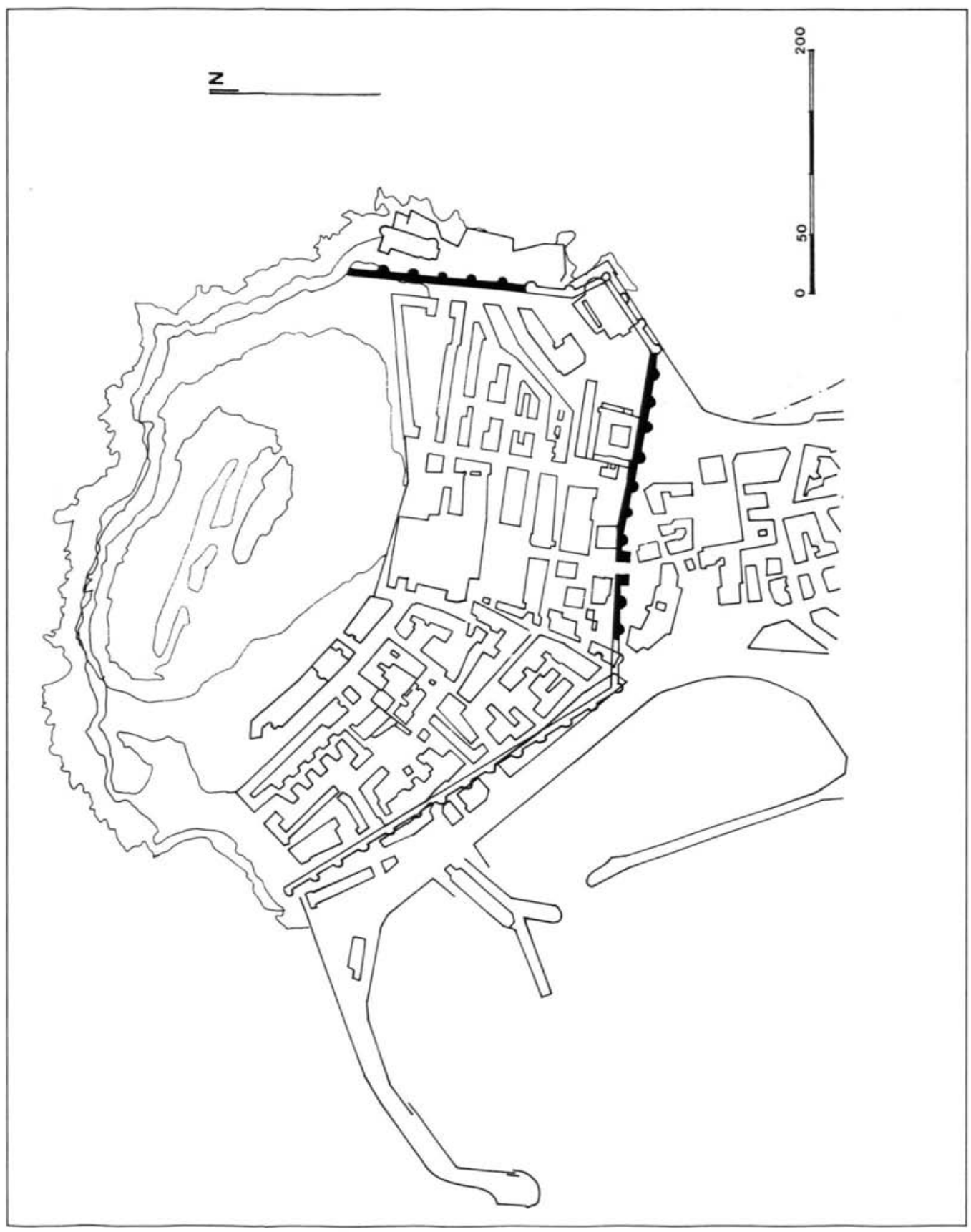

Figura 7. Muralla romana de Cimadevilla (Gijón-Asturias) 